\title{
The roles of BTG3 expression in gastric cancer: a potential marker for carcinogenesis and a target molecule for gene therapy
}

\author{
Wen-feng Gou ${ }^{1}$, Xue-feng Yang ${ }^{1}$, Dao-fu Shen ${ }^{1}$, Shuang Zhao ${ }^{1}$, Yun-peng Liu ${ }^{2}$, \\ Hong-zhi Sun ${ }^{1}$, Yasuo Takano ${ }^{3}$, Rong-jian Su${ }^{4}$, Jun-sheng Luo ${ }^{1}$ and Hua-chuan \\ Zheng $^{1}$ \\ ${ }^{1}$ Cancer Research Center, Key Laboratory of Brain and Spinal Cord Injury of Liaoning Province, and Laboratory Animal \\ Center, The First Affiliated Hospital of Liaoning Medical University, Jinzhou, China \\ 2 Department of Oncological Medicine, The First Affiliated Hospital of China Medical University, Shenyang, China \\ ${ }^{3}$ School of Health Science, Tokyo University of Technology, Ohta-ku, Tokyo \\ ${ }^{4}$ Experimental Center, Liaoning Medical University, Jinzhou, China \\ Correspondence to: Hua-chuan Zheng, email: zheng_huachuan@hotmail.com \\ Keywords: gastric cancer, BTG3, carcinogenesis, pathobiological behaviors, gene therapy \\ Received: February 11, $2015 \quad$ Accepted: March 10, $2015 \quad$ Published: March 30, 2015
}

This is an open-access article distributed under the terms of the Creative Commons Attribution License, which permits unrestricted use, distribution, and reproduction in any medium, provided the original author and source are credited.

\section{ABSTRACT}

BTG (B-cell translocation gene) can inhibit cell proliferation, metastasis and angiogenesis, cell cycle progression, and induce differentiation in various cells. Here, we found that BTG3 overexpression inhibited proliferation, induced S/G2 arrest, differentiation, autophagy, apoptosis, suppressed migration and invasion in MKN28 and MGC803 cells $(p<0.05)$. BTG3 transfectants showed a higher mRNA expression of p27, Bax, 14-3-3, Caspase-3, Caspase-9, Beclin 1, NF-kB, IL-1, -2, -4, -10 and -17, but a lower mRNA expression of p21, MMP-9 and VEGF than the control and mock ( $p$ $<0.05)$. At protein level, BTG3 overexpression increased the expression of CDK4, AIF, LC-3B, Beclin 1 and p38 $(p<0.05)$, but decreased the expression of p21 and $\beta$-catenin in both transfectants $(p<0.05)$. After treated with cisplatin, MG132, paclitaxel and SAHA, both BTG3 transfectants showed lower viability and higher apoptosis than the control in both time- and dose-dependent manners $(p<0.05)$. BTG3 expression was restored after 5-aza-2'-deoxycytidine or MG132 treatment in gastric cancer cells. BTG3 expression was decreased in gastric cancer in comparison to the adjacent mucosa $(p<0.05)$, and positively correlated with venous invasion and dedifferentiation of cancer $(p<0.05)$. It was suggested that BTG3 expression might contribute to gastric carcinogenesis. BTG3 overexpression might reverse the aggressive phenotypes and be employed as a potential target for gene therapy of gastric cancer.

\section{INTRODUCTION}

Gastric cancer is still ranked as the fourth most common after cancers of the lung, breast, and colon and rectum since the second half of the 20th century. It is also the second most common cause of cancer-related death although advanced diagnostic and operative techniques are widely applied $[1,2]$. It is helpful for the improvement of diagnosis, treatment and prevention to identify novel biomarkers and gene therapy targets during gastric carcinogenesis and subsequent progression.
BTG (B-cell translocation gene) family is composed of six proteins (BTG1, BTG2, BTG3, BTG4, Transducer of ErbB-2, and TOB2). The nucleocytoplamic translocation of BTG depends on cell growth states because both nuclear localization sequence and export signals exist in BTG3 protein $[3,4]$. BTG3 produces two mRNA transcripts due to 132-nucleotide deletion by alternative splicing [5-7]. In nucleus, BTG3 protein can bind to E2F1, Smad8 receptorregulated Smad transcription factor, CCR4 transcription factor-associated protein Cafl to finally suppress the proliferation and cell cycle progression [8-10]. Cheng 
Table 1: BTG3 expression in gastric non-neoplastic mucosa, primary and metastatic carcinomas.

\begin{tabular}{lllllll}
\hline & & \multicolumn{5}{c}{ BTG3 expression } \\
\cline { 3 - 7 } Groups & $\mathbf{n}$ & - & + & ++ & +++ & PR(\%) \\
\hline Non-neoplastic mucosa & 569 & 95 & 121 & 171 & 182 & 83.3 \\
Primary carcinoma & 613 & 410 & 134 & 49 & 20 & $33.1^{*}$ \\
Metastatic carcinoma in lymph node & 180 & 123 & 49 & 7 & 1 & 31.7 \\
\hline
\end{tabular}

* compared with non-neoplastic mucosa, $p<0.001$.

$\mathrm{PR}=$ positive rate

et al. [11] found that BTG3 can be phosphorylated and activated via the interaction with checkpoint kinase 1 (CHK1). Additionally, BTG3 maintains genomic stability by promoting Lys63-linked ubiquitination and CHK1 activation. Lin et al. [12] demonstrated that BTG3 loss physiologically induced cellular senescence via ERKAP1 signaling for acute induction of p16. Reportedly, BTG3 binds and suppresses Akt [13] and Ras/MAP kinase signaling [14] in cytoplasm.

BTG3-deficient mice might develop lung tumors by postnatal 21 months [15]. The down- regulated expression of BTG3 is documented in ovarian, lung, prostate or renal, hepatocellular cancer tissues or cells, and its expression is restored by the treatment with genistein and 5-aza-2'- deoxycytidine [6, 15-19]. Exogenous BTG3 overexpression inhibits the expression levels of matrix metalloproteinase (MMP) -2 and plasminogen activator inhibitor-1 in lung cancer cells [15]. Yanagida et al. [20] showed that BTG3 knockdown suppressed proliferation and tumorigenicity of ovarian clear cell carcinoma. Reportedly, BTG3 expression was inversely correlated with differentiation, distant metastasis and favorable prognosis of hepatocellular cancer (HCC). Ectopic BTG3 expression decreased proliferation, invasion and induced $\mathrm{G}_{1} / \mathrm{S}$ cycle arrest of $\mathrm{HCC}$ cells in vitro [18], and inhibited the growth of lung cancer in vivo [21]. To clarify the roles of $B T G 3$ in gastric carcinogenesis, we investigated the effects of BTG3 overexpression on cell proliferation, apoptosis, autophagy, senescence, invasion, migration and lamellipodia formation of gastric cancer cells and screened the expression of the phenotyperelated genes. In addition, we examined the expression of $B T G 3$ mRNA and protein in gastric cancer, non-cancerous mucosa and cancer cell lines, and compared them with clinicopathological parameters of cancer. Its promoter methylation was measured in gastric cancer cells and tissues. Finally, the in vitro and in vivo effects of BTG3 overexpression on aggressive behaviors of gastric cancer cells were determined in nude mice.

\section{RESULTS}

The expression and methylation of $B T G 3$ in gastric cancer cells

$29 \mathrm{kDa}$ protein band of BTG3 was seen in AGS, BGC823, GT-3 TKB, HCG-27, KATO-III, MGC803, MKN28, MKN45, SCH, and STKM-2 (Fig. 1A), To check BTG3 mRNA expression, we designed the primers of RT-PCR targeting BTG3a (572-703, NM_001130914.1), which is deleted in BTG3b (Fig. 1B). BTG3 mRNA was detectable in gastric cancer and epithelial cells, except HGC-27 (Fig. 1C). Three BTG3 bands were observed in MKN45 and MGC803 cells. The upper and lower DNA fragments were eluted and amplified (Fig. 1D). All arrow-indicated bands proved to be $B T G 3 \mathrm{~b}$ by direct DNA sequencing (Fig. 1E). We detected the methylation of two promoter sites of $B T G 3$ in all cells by MSP, but unmethylation only in GES-1, GT-3 TKB, MKN45, and SCH (Fig. 1F). BTG3 expression was restored after the exposure to the demethylating agent 5-Aza-dC in GES-1, AGS, BGC823, KATO-III, MGC803 and MKN28 (Fig 1G, $p<0.05$ ). The treatment of the proteasome inhibitor MG132 increased BTG3 expression in MGC803 and SGC7901 cells by Western blot (Fig. 1H) and immunofluorescence (Fig. 1I).

The effects of BTG3 overexpression on the phenotypes and relevant molecules of gastric cancer cells

BTG3-expressing plasmid was successfully transfected into MKN28 and MGC803 cells, evidenced by real-time PCR and Western blot (Fig. 2A). Both transfectants showed a high disrupted mitosis (Fig. 2B), a low growth (Fig. 2C, $p<0.05$ ) and $\mathrm{S} / \mathrm{G} 2$ arrest (Fig. 2D, $p$ $<0.05$ ) in comparison to the control and mock. There was 


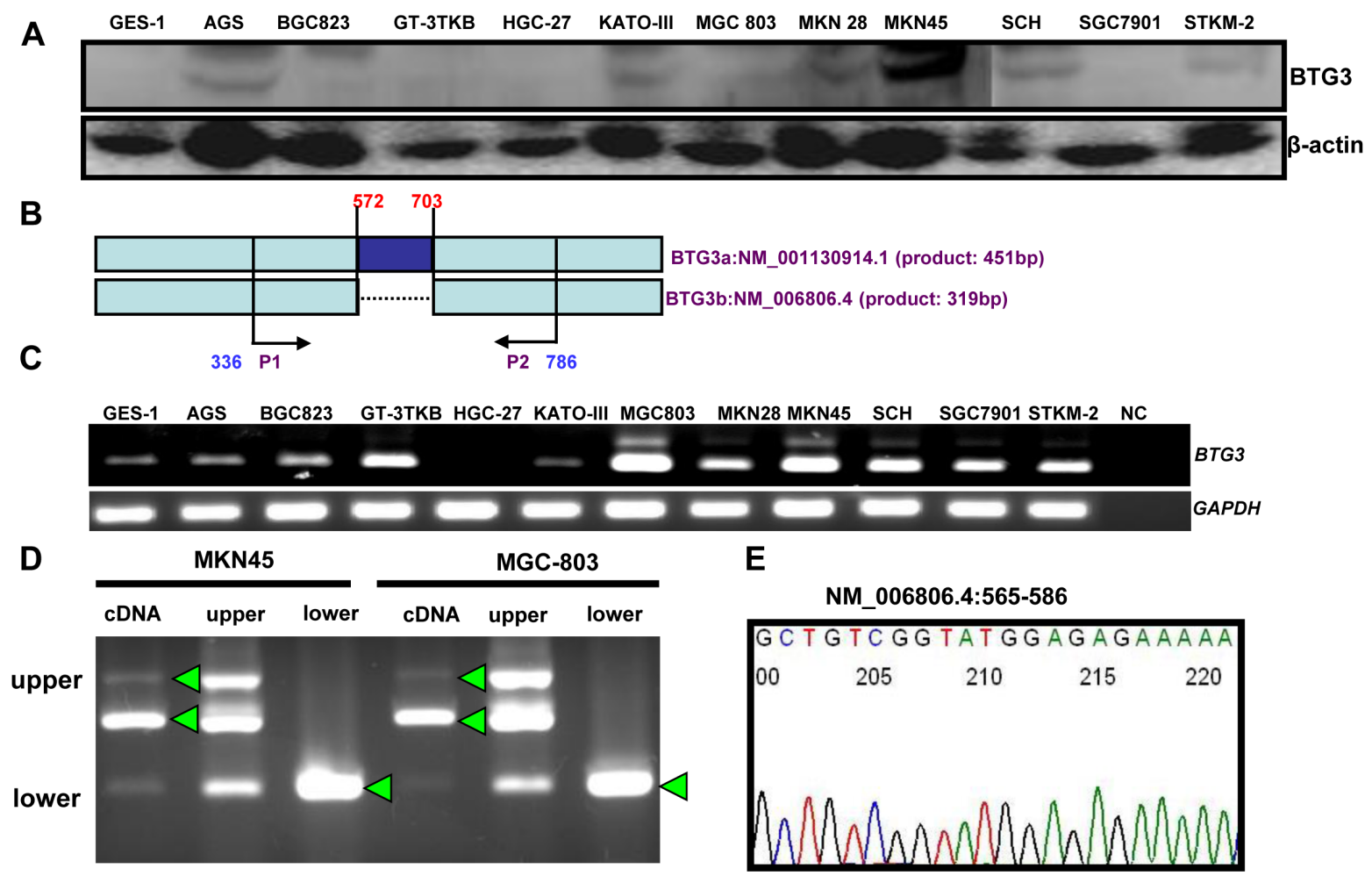

F GES-1 AGS BGC-823 GT-3TKB HGC-27 KATO-III MGC-803 MKN28 MKN45 SCH SGC7901 STKM-2

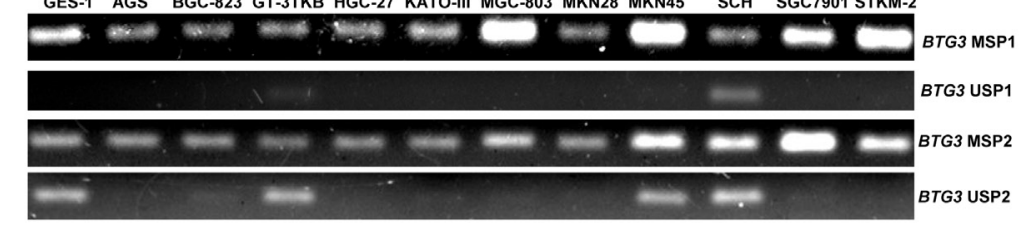

$\mathbf{G}$
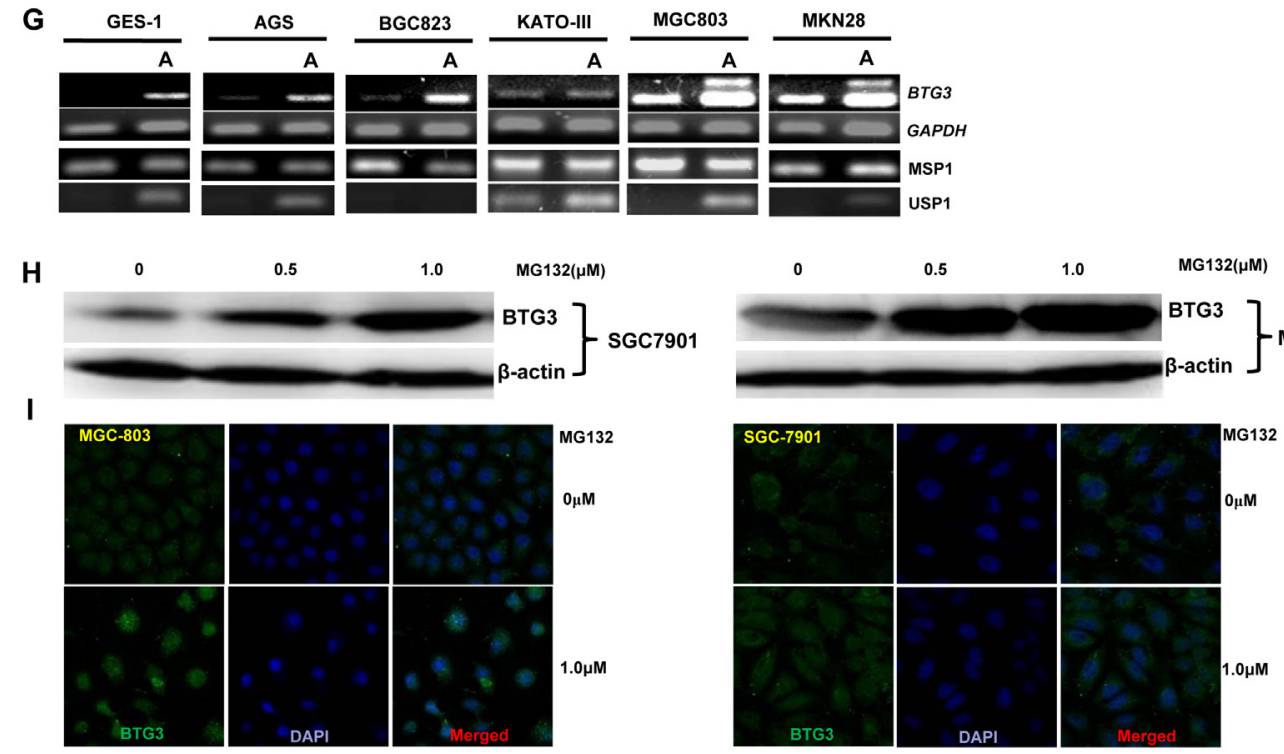

Figure 1: BTG3 expression and methylation in gastric cancer cell lines. BTG3 protein expression (29 kDa) was detectable in gastric cancer cell lines at distinct levels with $\beta$-actin $(42 \mathrm{kDa})$ as an internal control (A). We designed the BTG3 primers to determine its two different variants (B). Although three bands were observed for BTG3 amplicon, direct sequencing indicated that they are the same products (C-E). In addition, we found BTG3 methylation in gastric cancer or epithelial cell lines (F), but GES-1, AGS, BGC823, KATO-III, MGC803 and MKN28 cells showed a higher expression of $\boldsymbol{B T G} 3$ mRNA by RT-PCR after treated with 5-Aza-dC (G). MG 132 exposure increased BTG3 expression (H and I). NC, negative control; U, unmethylated; M, methylated; MSP, methylation-specific PCR; A, 5-Aza$\mathrm{dC} ; *, p<0.05$. 
Table 2: Relationship between BTG3 expression and clinicopathological features of gastric cancers.

\begin{tabular}{|c|c|c|c|c|c|c|c|}
\hline \multirow{2}{*}{$\begin{array}{l}\text { Clinicopathological } \\
\text { features }\end{array}$} & \multirow[b]{2}{*}{$\mathbf{n}$} & \multicolumn{6}{|c|}{ BTG3 expression } \\
\hline & & - & + & ++ & +++ & PR(\%) & $p$ value \\
\hline Age(year) & & & & & & & 0.426 \\
\hline$<65$ & 351 & 240 & 74 & 24 & 13 & 31.6 & \\
\hline$\geq 65$ & 262 & 170 & 60 & 25 & 7 & 35.1 & \\
\hline Sex & & & & & & & 0.922 \\
\hline Male & 427 & 284 & 93 & 36 & 14 & 33.5 & \\
\hline Female & 186 & 126 & 41 & 13 & 6 & 32.3 & \\
\hline Depth of invasion & & & & & & & 0.569 \\
\hline$T_{\text {is }-1}$ & 294 & 203 & 56 & 20 & 15 & 31.0 & \\
\hline $\mathrm{T}_{2-4}$ & 310 & 201 & 75 & 29 & 5 & 35.2 & \\
\hline Lymphatic invasion & & & & & & & 0.541 \\
\hline - & 354 & 244 & 67 & 27 & 16 & 31.1 & \\
\hline+ & 259 & 166 & 67 & 22 & 4 & 35.9 & \\
\hline Venous invasion & & & & & & & 0.004 \\
\hline - & 346 & 251 & 63 & 18 & 14 & 27.5 & \\
\hline+ & 267 & 159 & 71 & 31 & 6 & 40.4 & \\
\hline Lymph node metastasis & & & & & & & 0.679 \\
\hline- & 348 & 232 & 72 & 29 & 15 & 33.3 & \\
\hline+ & 265 & 178 & 62 & 20 & 5 & 32.8 & \\
\hline Distant metastasis & & & & & & & 0.268 \\
\hline- & 578 & 385 & 125 & 48 & 20 & 33.4 & \\
\hline+ & 35 & 25 & 9 & 1 & 0 & 28.6 & \\
\hline TNM staging & & & & & & & 0.145 \\
\hline I-II & 355 & 248 & 65 & 26 & 16 & 30.1 & \\
\hline III-IV & 244 & 152 & 65 & 23 & 4 & 37.7 & \\
\hline Lauren's classification & & & & & & & - \\
\hline Intestinal-type & 186 & 102 & 53 & 21 & 10 & 45.2 & \\
\hline Diffuse-type & 219 & 177 & 28 & 9 & 5 & $19.2^{*}$ & \\
\hline Mixed-type & 204 & 129 & 51 & 19 & 5 & 36.8 & \\
\hline
\end{tabular}

$\mathrm{PR}=$ positive rate, $\mathrm{T}_{\mathrm{is}}=$ carcinoma in situ, $\mathrm{T}_{1}=$ lamina propria and submucosa, $\mathrm{T}_{2}=$ muscularis propria and subserosa, $\mathrm{T}_{3}=$ exposure to serosa, $\mathrm{T}_{4}=$ invasion into serosa, $\mathrm{TNM}=$ tumor-node-metastasis *, compared with intestinal-type or mixed-type carcinomas, $\mathrm{P}<0.001$ 
a higher apoptotic level evidenced by Annexin V-FITC staining (Fig. 2E, $p<0.05$ ), a better differentiation by alkaline phosphatase (ALP) activity (Fig. 2F, $p<0.05$ ) and a higher autophagy by punctate LC3B-GFP accumulation (Fig. 2G) and LC-3B expression (Fig. 2L) in both BTG3 transfectants than the control and/or mock. According to the results of wound healing and transwell chamber assay, BTG3 transfectants also exhibited weaker ability to migrate and invade than the control and mock (Fig. $2 \mathrm{H}$ and $2 \mathrm{I}, p<0.05)$. Both transfectants showed weak F-actin staining (Fig. 2J) and strong $\beta$-galactosidase staining in comparison to the control and/or mock (Fig. 2K). Additionally, BTG3 transfectants showed a higher expression of p27, Cyclin D1, Cyclin B1, Bax, Bcl-2, 143-3, Caspase-3, Caspase-9, Beclin 1, NF- $\kappa B, I L-1, I L-2$, $I L-4, I L-10$ and $I L-17$, but a lower expression of $p 21$, MMP-9 and VEGF than the control and mock (Fig. 2M, $p$ $<0.05$ ). At the protein level (Fig. 2L), BTG3 increased the expression of CDK4, AIF, LC-3B, Beclin 1, and p38 ( $p<$ $0.05)$, but decreased the expression of $\mathrm{p} 21$ and $\beta$-catenin in both MKN28 and MGC803 cells ( $p<0.05)$.

After treated with different anti-cancer agents (cisplatin, MG132, paclitaxel and SAHA), both BTG3 transfectants showed lower viability and higher apoptosis than the control in both time- and dose-dependent manners (Fig. 3A-B, $p<0.05$ ). BTG3 overexpression decreased the expression of GRP78 and TOP2, but increased the expression of $F B X W 7, C D 147$ and TOP1 in both MKN28 and MGC803 cells (Fig. 3C, $p<0.05$ ).

\section{The expression and methylation of BTG3 in gastric cancer}

Only $B T G 3 b$ was amplified in 24 pairs of gastric cancer and corresponding mucosa. BTG3 mRNA expression was stronger in cancer than in the adjacent mucosa (Fig. 4A, $p<0.05$ ). To examine BTG3 methylation status, we designed methylation-specific primers of different BTG3 promoter regions ( $-474-596$ and -608-709) and found BTG3 methylation in all cases (Fig. 4B). There was no correlation between the mRNA expression and promoter methylation of BTG3 $(p>$ 0.05 , data not shown). Among 38 cases of frozen gastric samples, $29 \mathrm{kDa}$ bands of BTG3 were weaker in gastric cancer than matched mucosa (Fig. 4C, $p<0.05$ ).

As indicated in Fig. 5, BTG3 expression was positively observed in the cytoplasm of superficial mucosa, deep propria glands, well-, moderately-, poorlydifferentiated, mucinous, signet ring cell carcinoma and metastatic carcinoma in lymph node. BTG3 expression was detectable in gastric non-neoplastic mucosa $(83.3 \%$, $474 / 569)$, primary cancer $(33.1 \%, 203 / 613)$, and metastatic cancer in lymph node $(31.7 \%, 57 / 180)$, respectively. Statistically, BTG3 expression was decreased in gastric cancer in comparison to the adjacent mucosa (Table 1, $p$ $<0.05)$.

\section{The correlation of BTG3 expression with clinicopathological parameters of gastric cancer}

As summarized in Table 2, there was a positive correlation between BTG3 expression and venous invasion of gastric cancer $(p<0.05)$. In contrast, BTG3 positivity was not linked to age, sex, depth of invasion, lymphatic invasion, lymph node metastasis, distant metastasis or TNM staging of gastric cancer $(p>0.05)$. The diffuse-type carcinomas showed less BTG3 expression than intestinaland mixed-type ones $(p<0.05)$, while no difference was observed in BTG3 expression between intestinal and diffuse components of mixed-type carcinomas ( $p>$ 0.05 , data not shown). It was the same between primary and corresponding metastatic cancers $(p>0.05$, data not shown).

Follow-up information was available on 515 gastric cancer patients for periods ranging from 2 months to 10.8 years $($ median $=68.5$ months $)$. Univariate analysis using Kaplan-Meier indicated no significant difference between the cumulative survival rates of patients and BTG3 expression regardless of invasive depth $(p>0.05$, Fig. 5J). Multivariate analysis using Cox's proportional hazard model indicated that lymph node metastasis, distant metastasis and tumor-node-metastasis(TNM) staging were independent prognostic factors for overall gastric cancers (Table 3, $p<0.05$ ).

\section{BTG3 in vivo suppresses the growth of gastric cancer cells in nude mice}

MKN28, MGC803 and their BTG3 transfectants were subcutaneously transplanted into immune-deficient nude mice. The tumor volume and weight of both parental cells were larger and heavier than those of their BTG3 transfectants by ruling and weighting respectively $(p<0.05$, Fig. 6A-H). Immunohistochemically both transfectants showed stronger BTG3 expression (Fig. 6I), lower proliferation evidenced by ki-67 marker (Fig. 5J) and more authophagy by LC-3B staining (Fig. 6K) than the control. There appeared a higher apoptotic level in BTG3 transfectants than the control by TUNEL (Fig. 6L).

\section{DISCUSSION}

Here, we found that BTG3 protein was mainly localized in the cytoplasm of superficial mucosa, infiltrating inflammatory cells, deep propria glands, fundic glands, primary and metastatic cancers. Transcrptionally, $B T G 3$ b was only detectable in gastric cancer cells and tissues, while BTG3a and $3 \mathrm{~b}$ in lung cancer cells and 
A
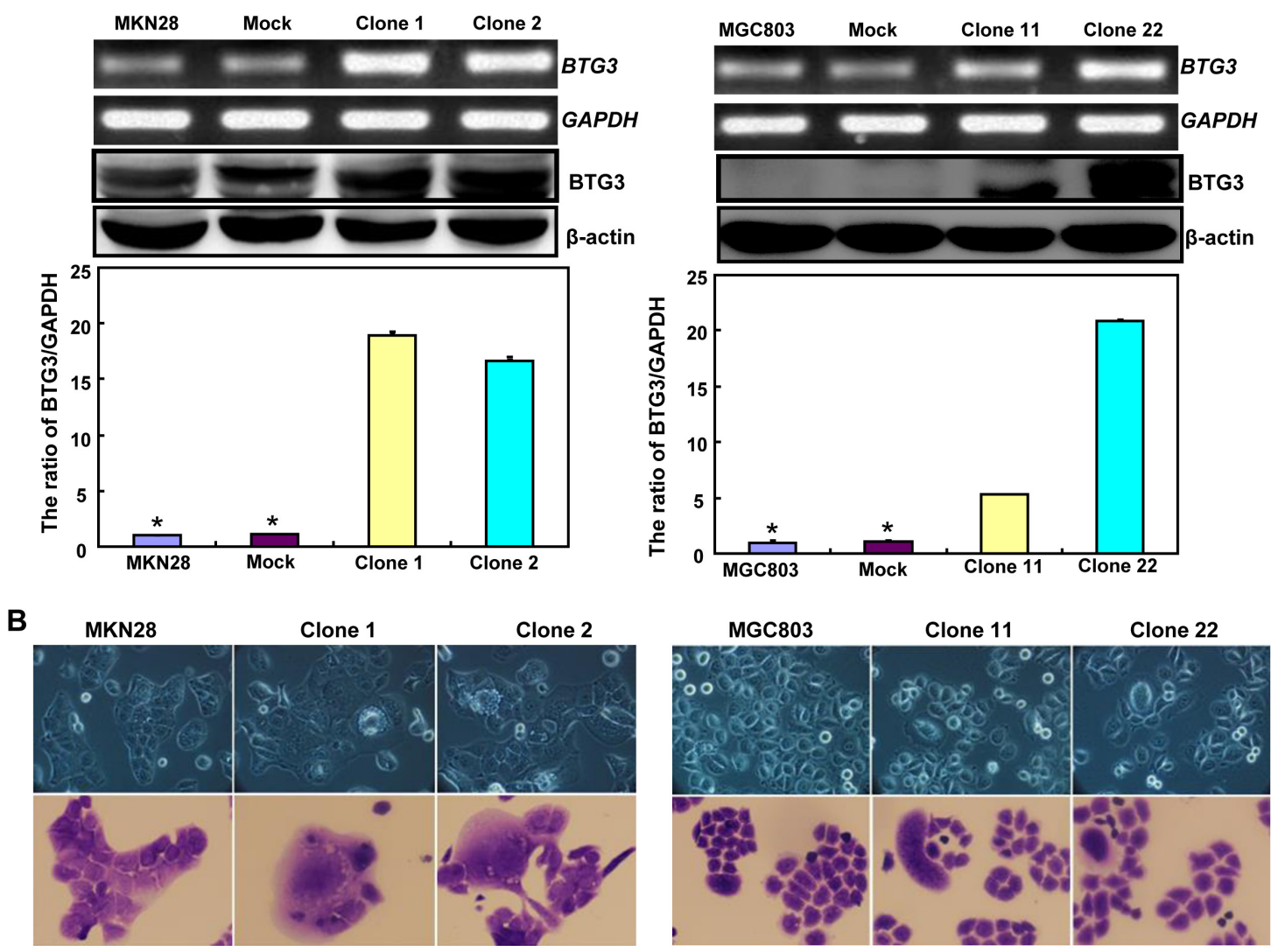

C
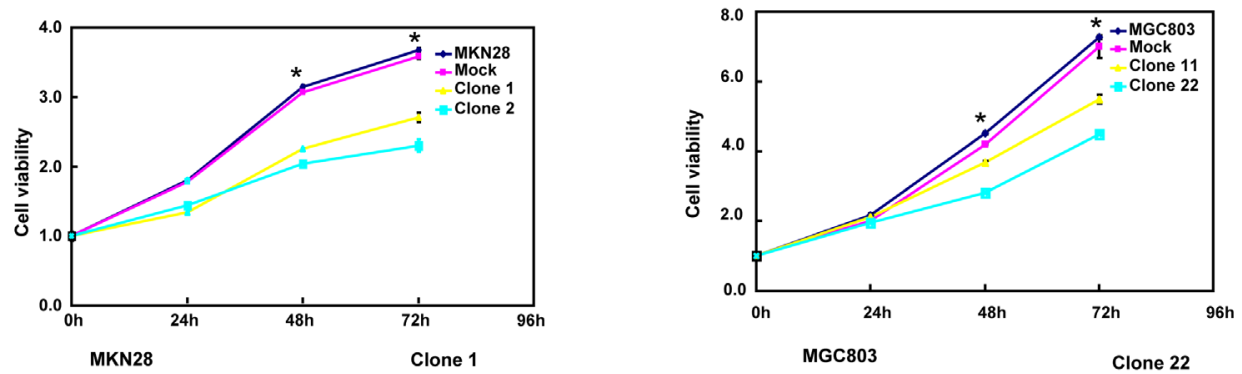

D
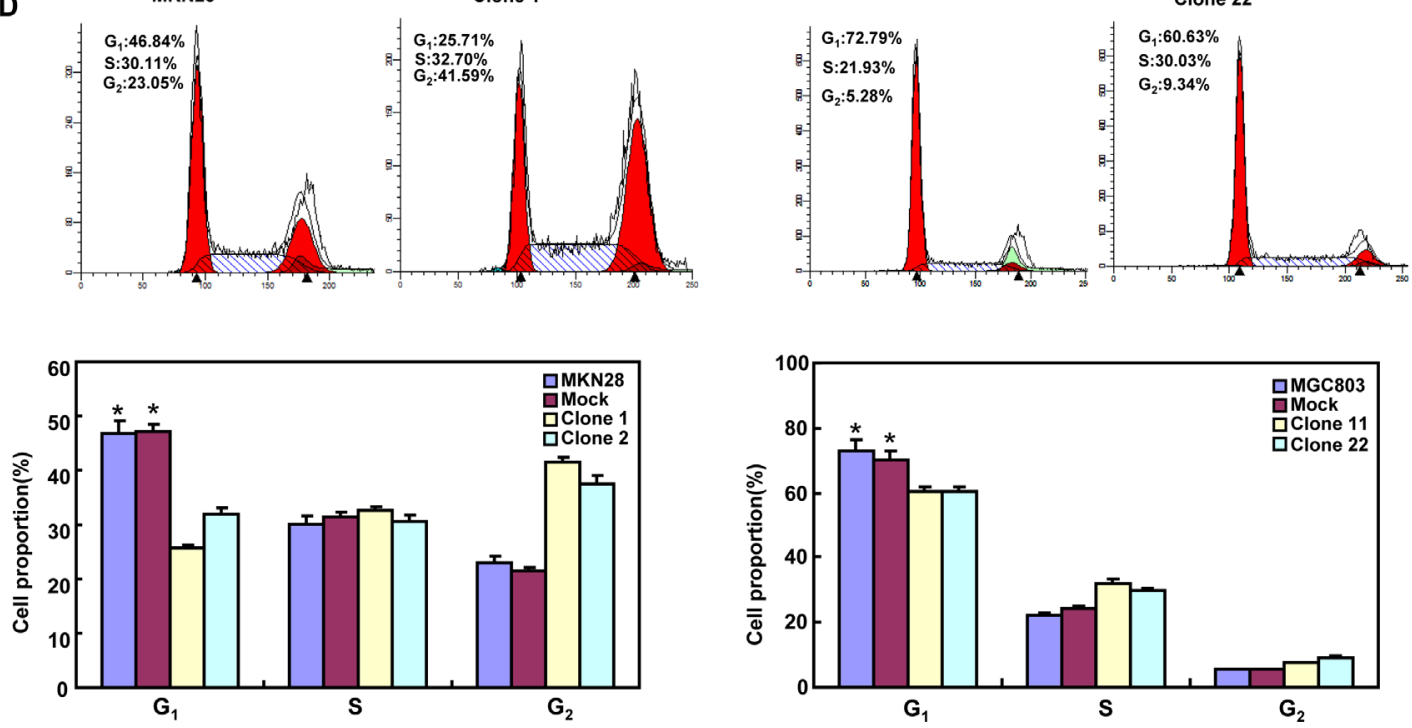
E
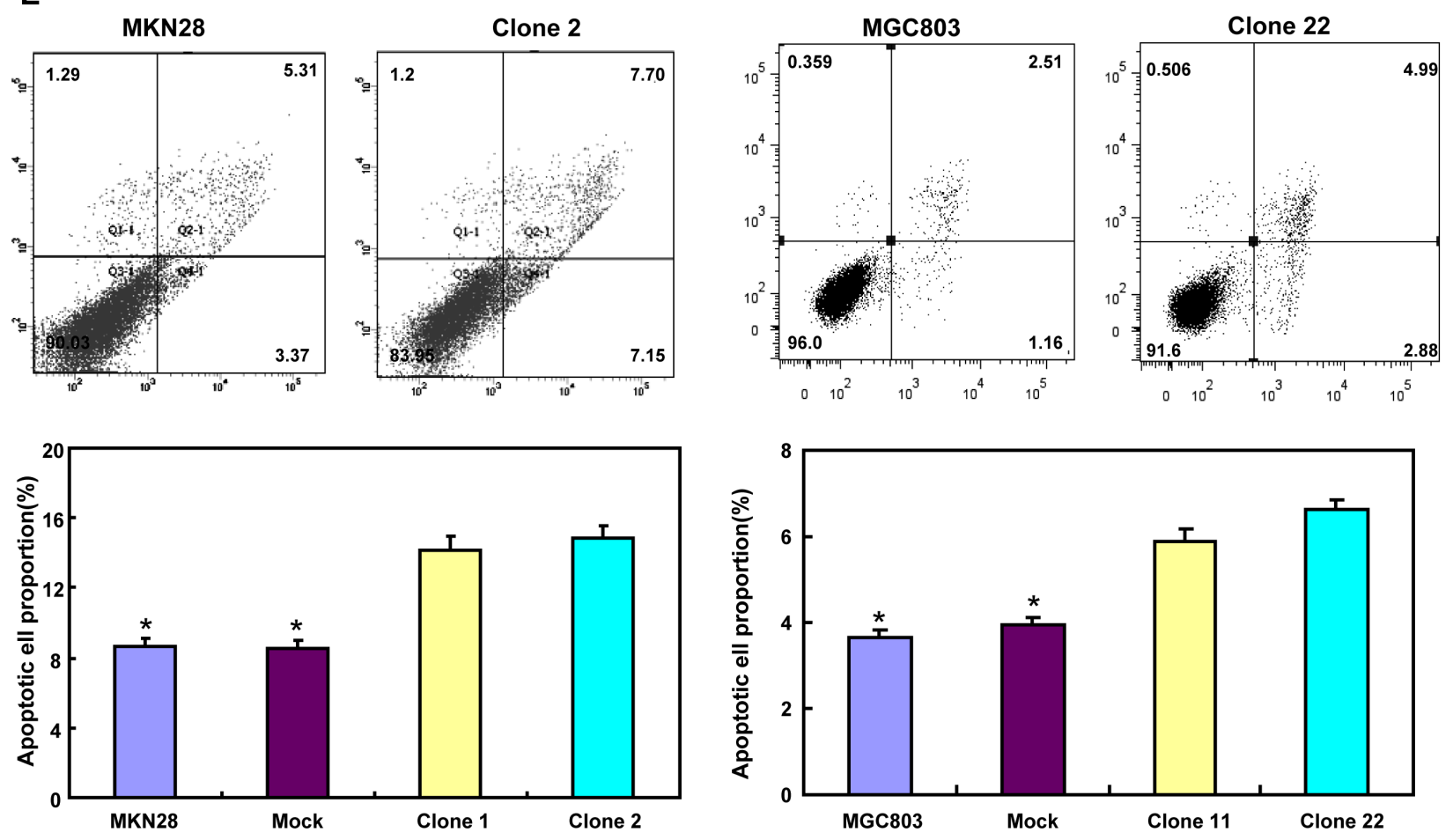

F
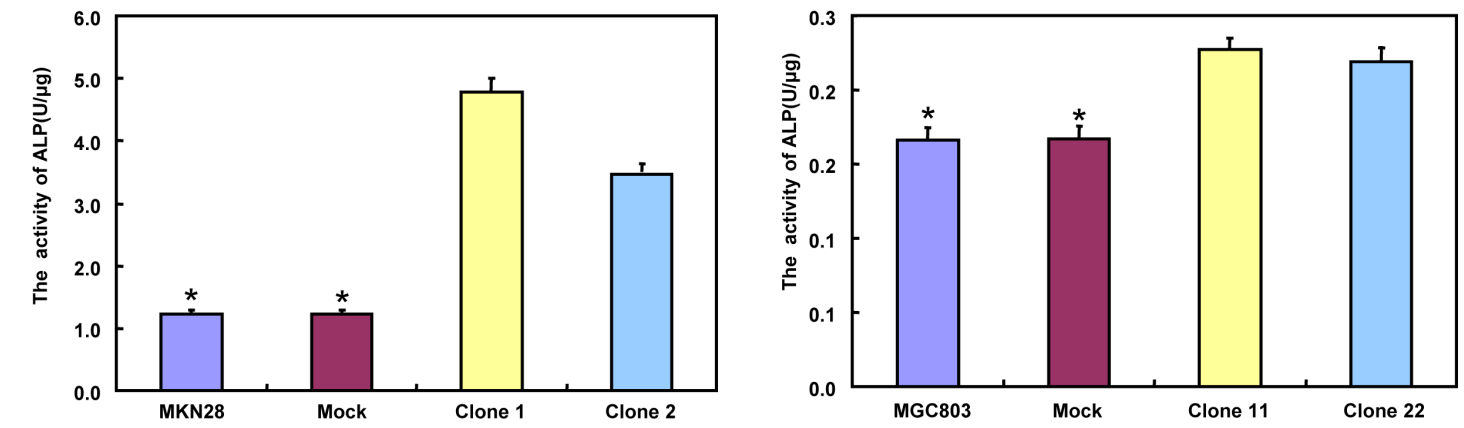

G

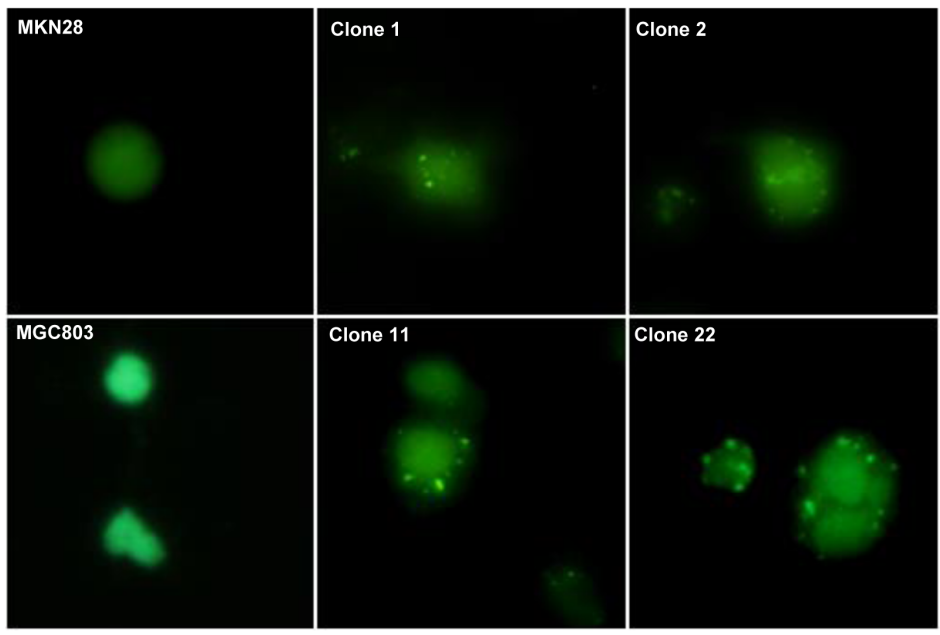



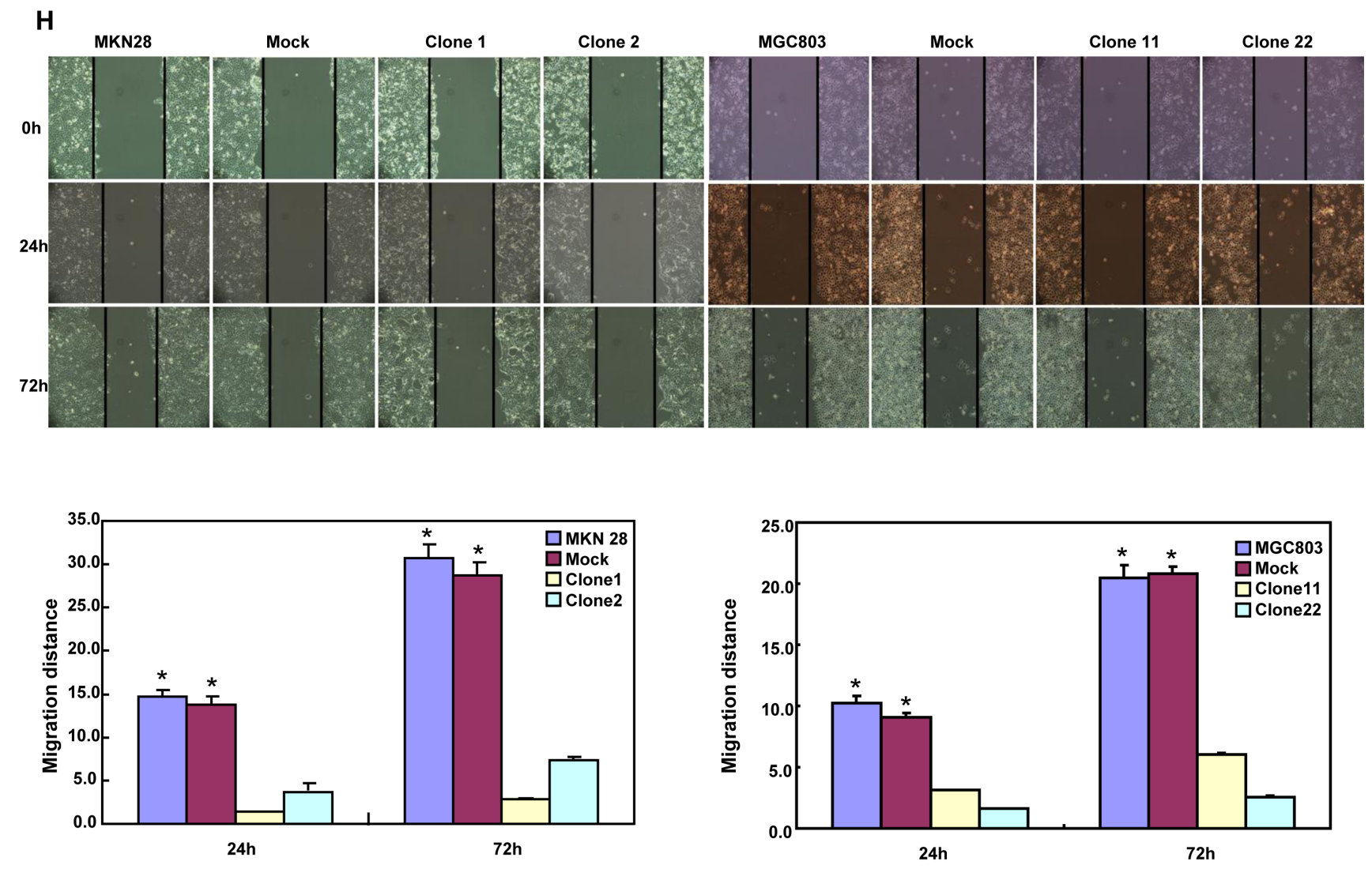

I
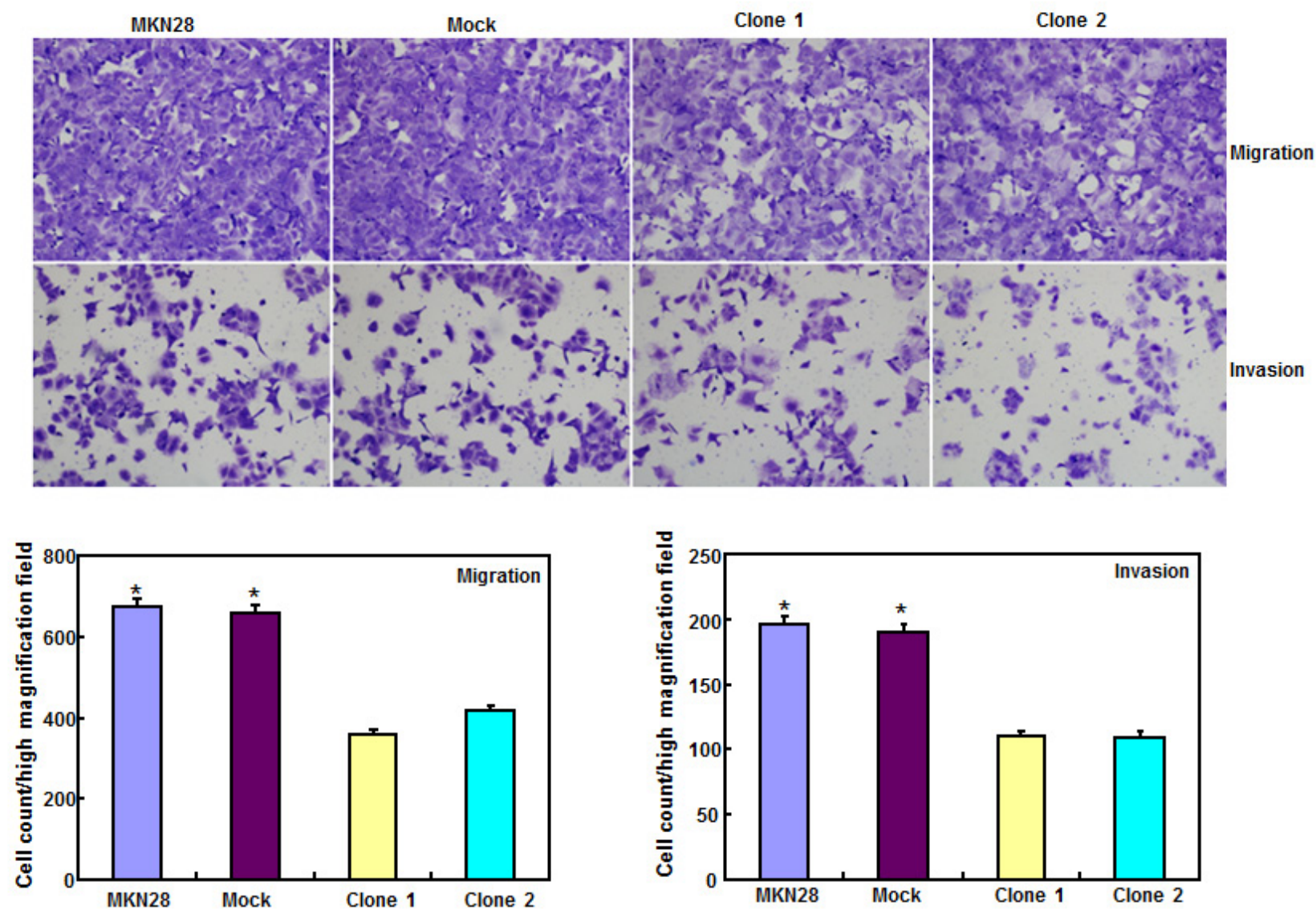

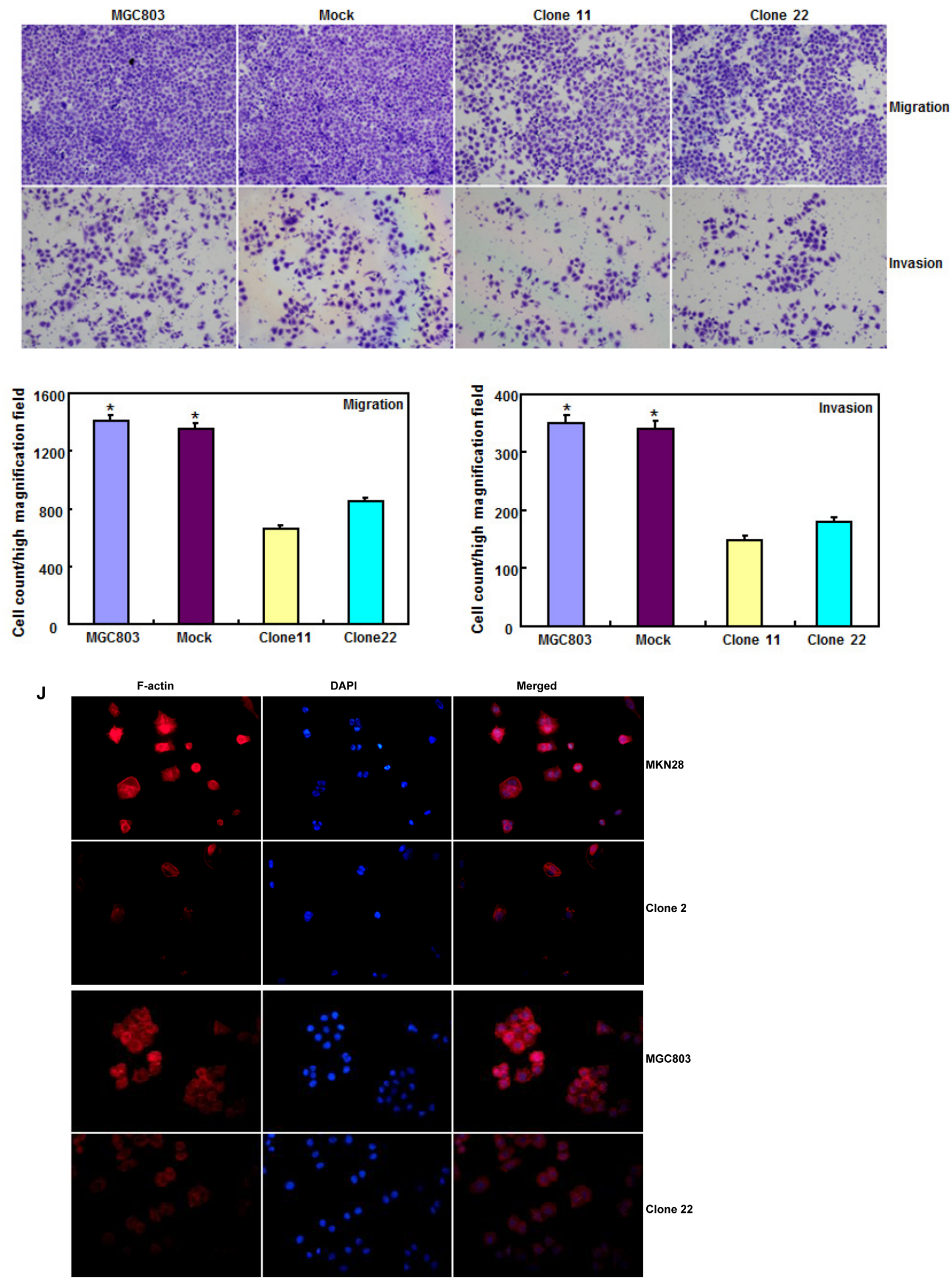

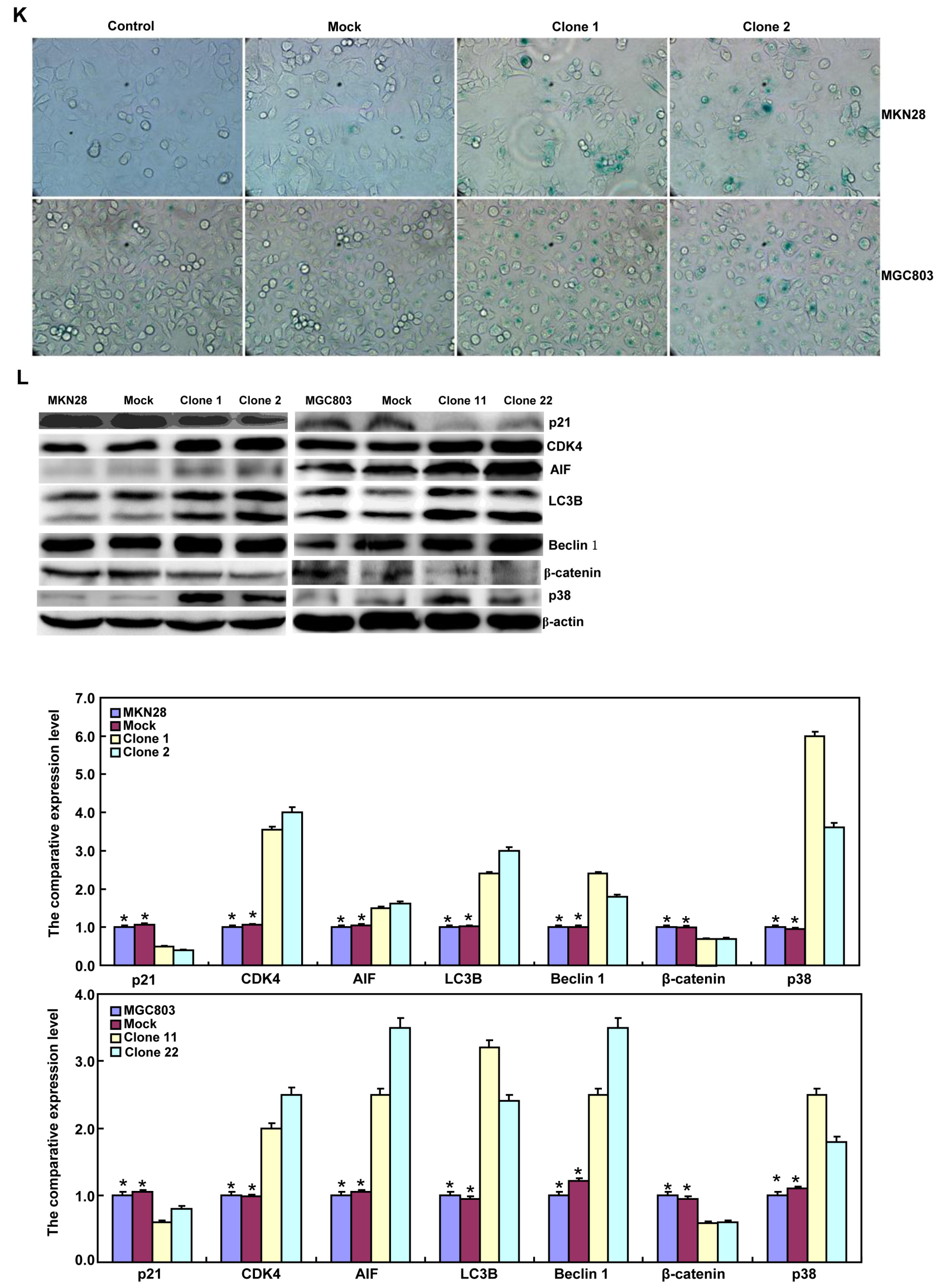
M
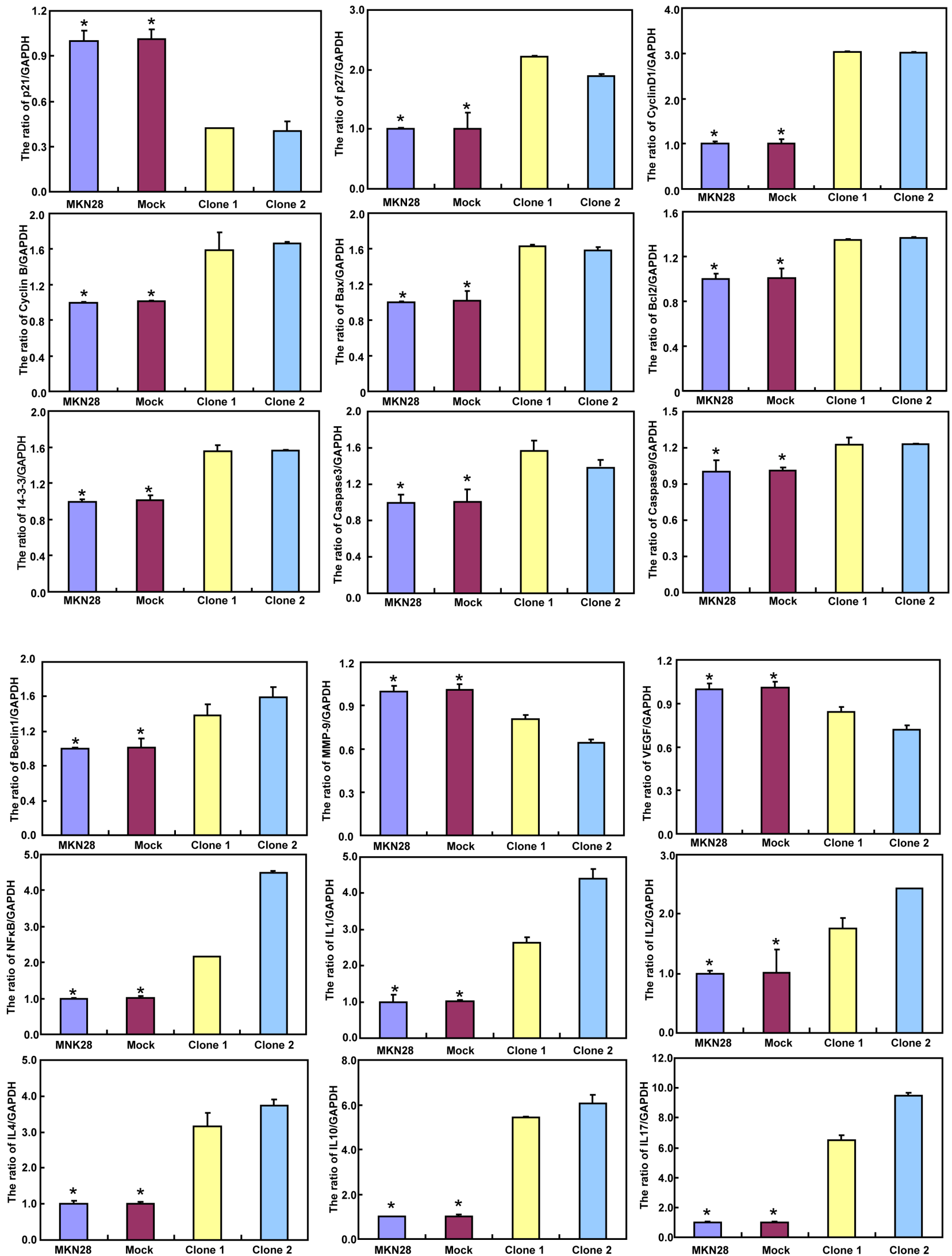

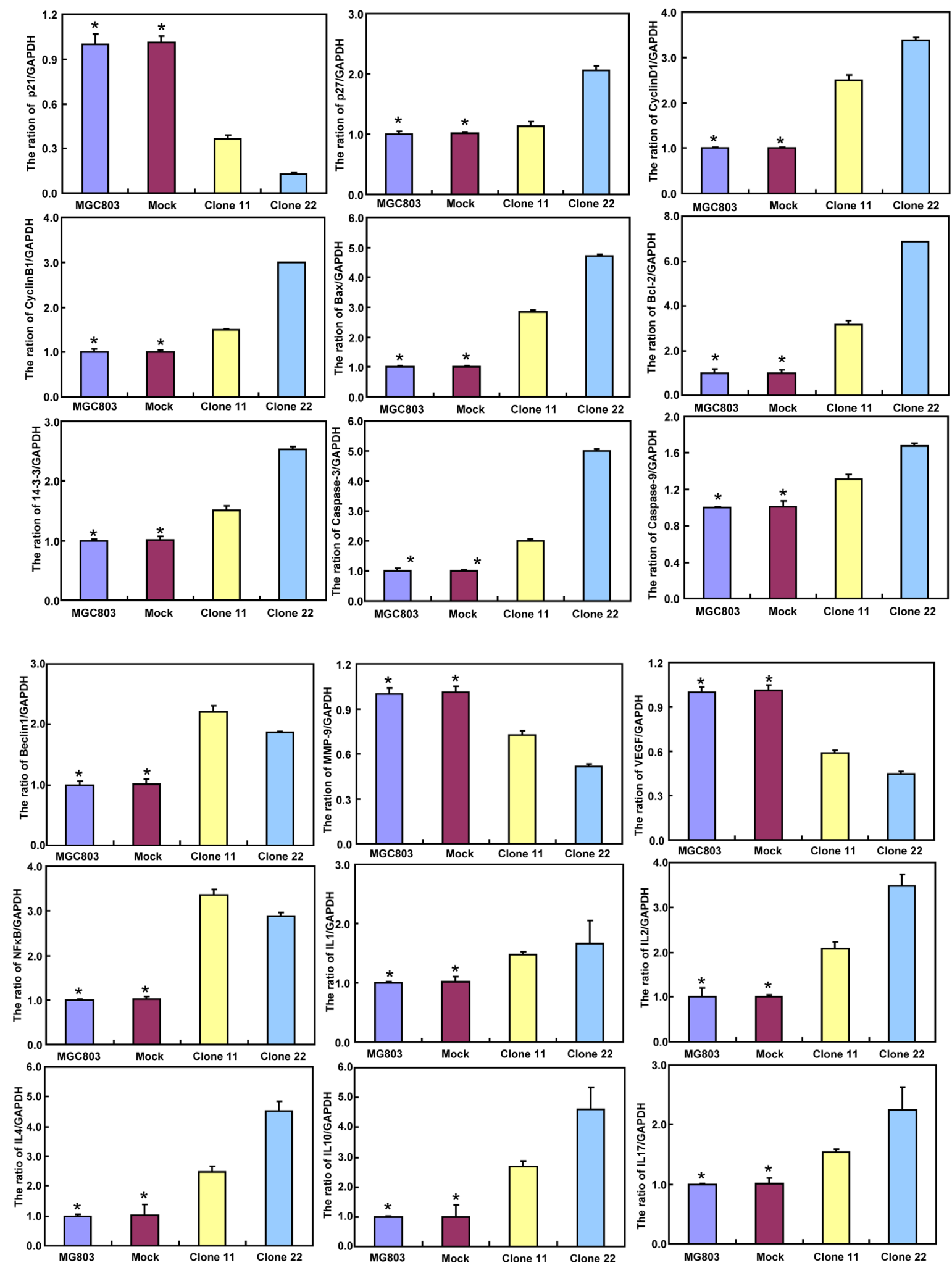

Figure 2: The effects of BTG3 overexpression on the phenotypes and expression of phenotype-related molecules in gastric cancer cells. After transfection of pcDNA3.1-BTG3 into MKN28 and MGC803 cells, BTG3 expression became strong by RTPCR and Western blot (A). BTG3 transfectants showed a high proportion of S-phase cells (B), slow growth $(\mathbf{C}), \mathrm{S} / \mathrm{G}_{2}$ arrest (D), apoptotic induction $(\mathbf{E})$, better differentiation $(\mathbf{F})$, high punctate LC3B-EGFP $(\mathbf{G})$, weak ability to migrate and invade $(\mathbf{H}$, I), weak lamellipodia formation $(\mathbf{J})$ and high senescence $(\mathbf{K})$ in comparison with control and mock. The expression of phenotype- related molecules was screened by Western blot $(\mathbf{L})$ and real-time RT-PCR $(\mathbf{M})$. $^{*}, p<0.05$, compared with thr transfectants. 
A
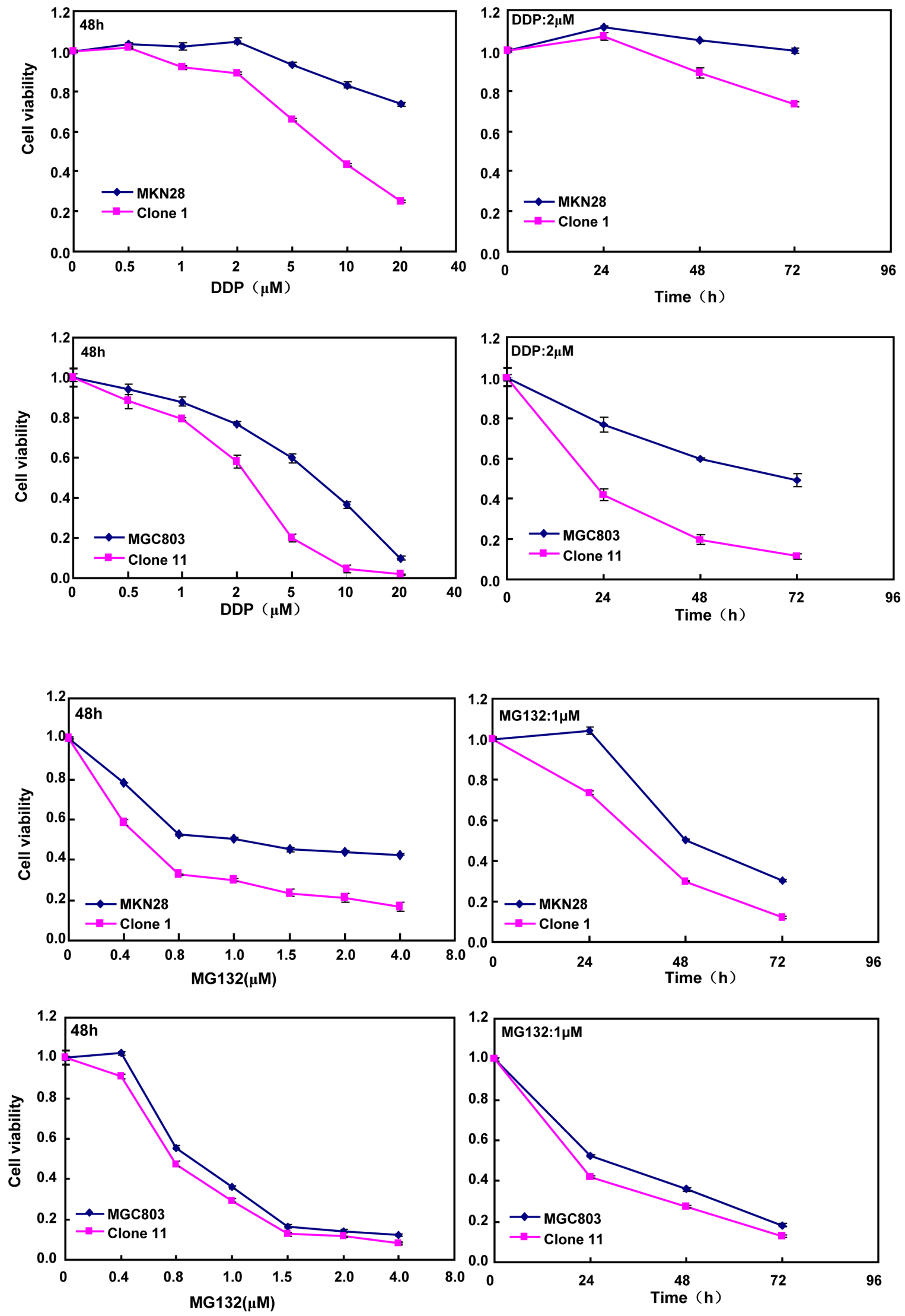

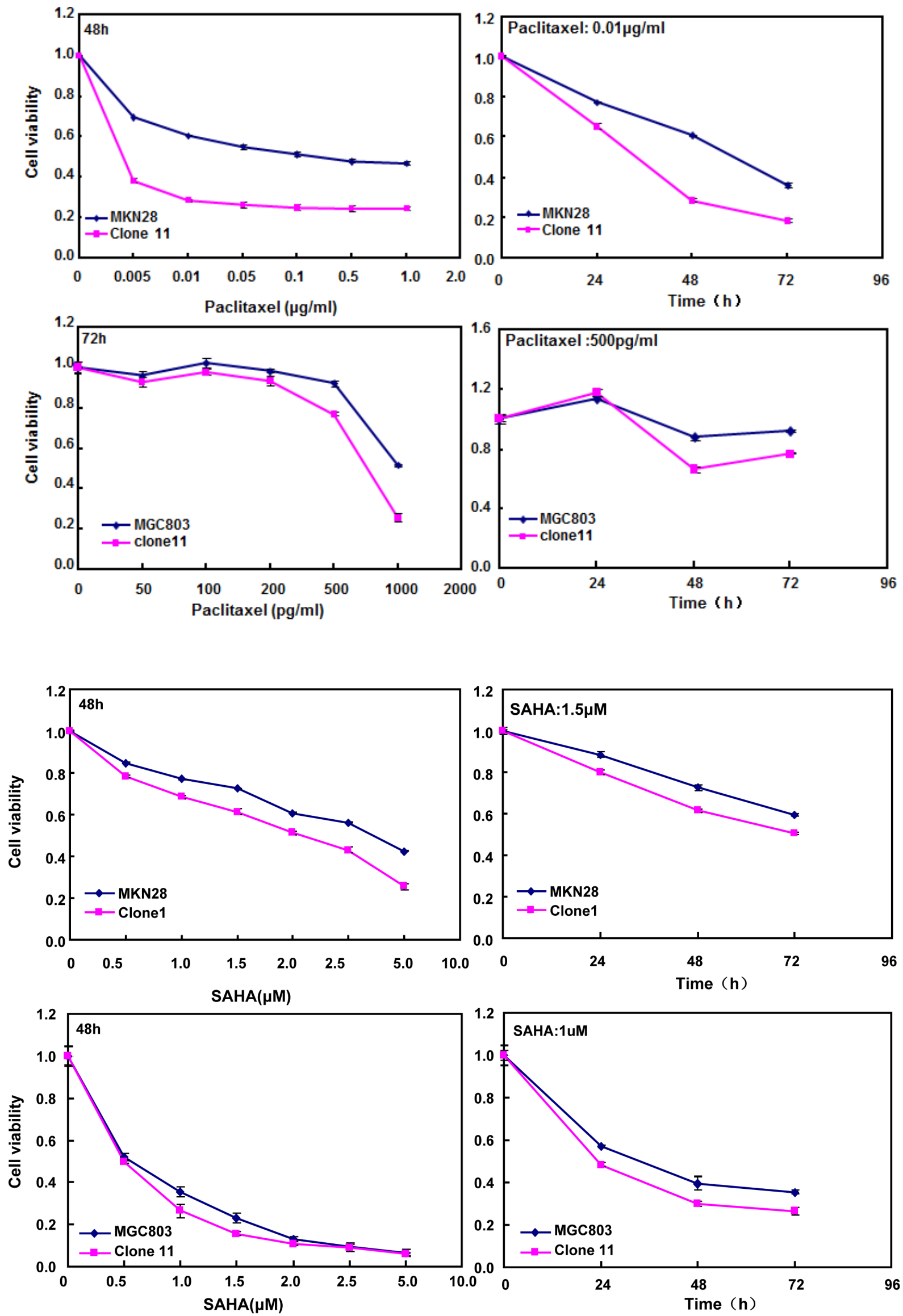
B
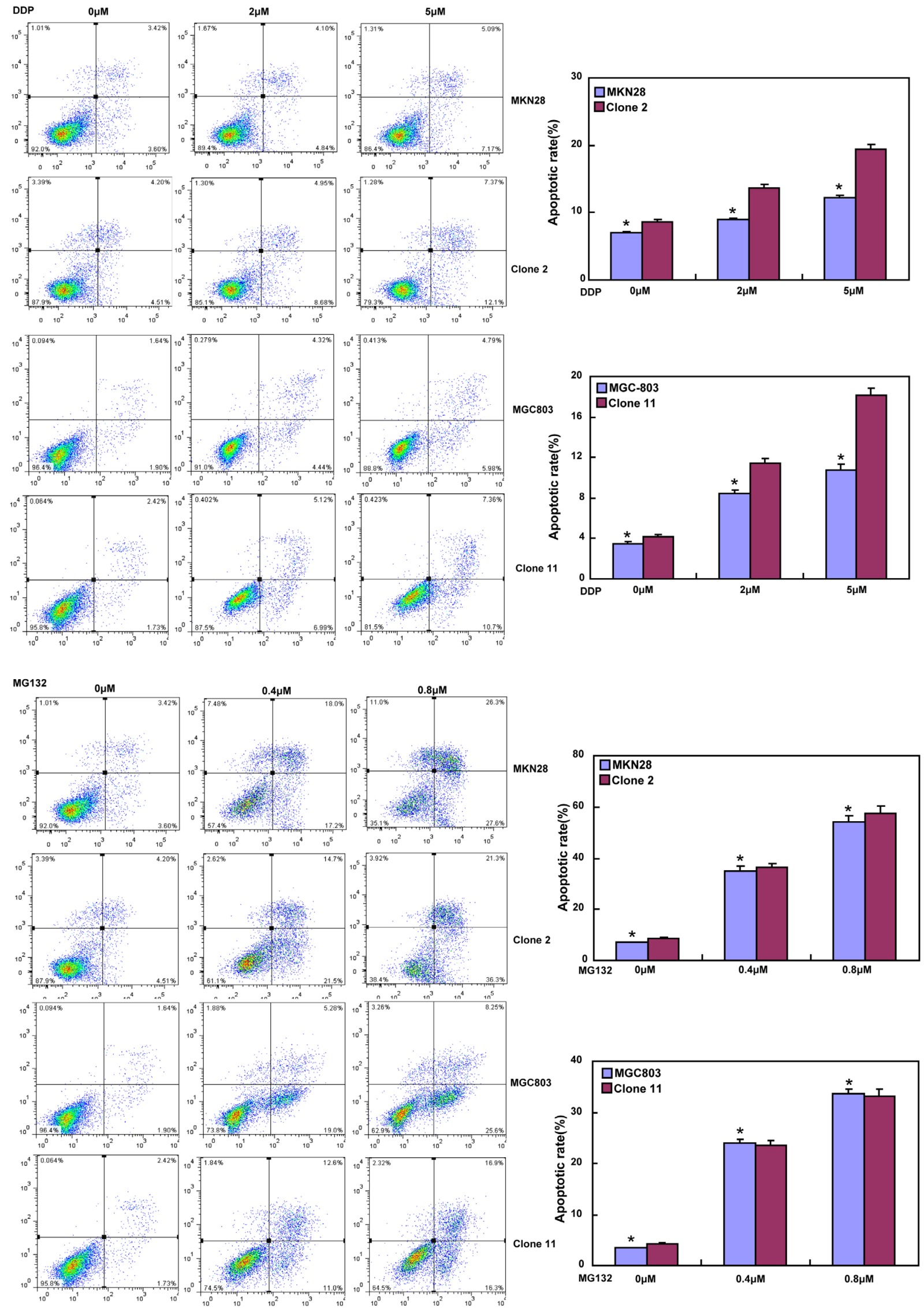

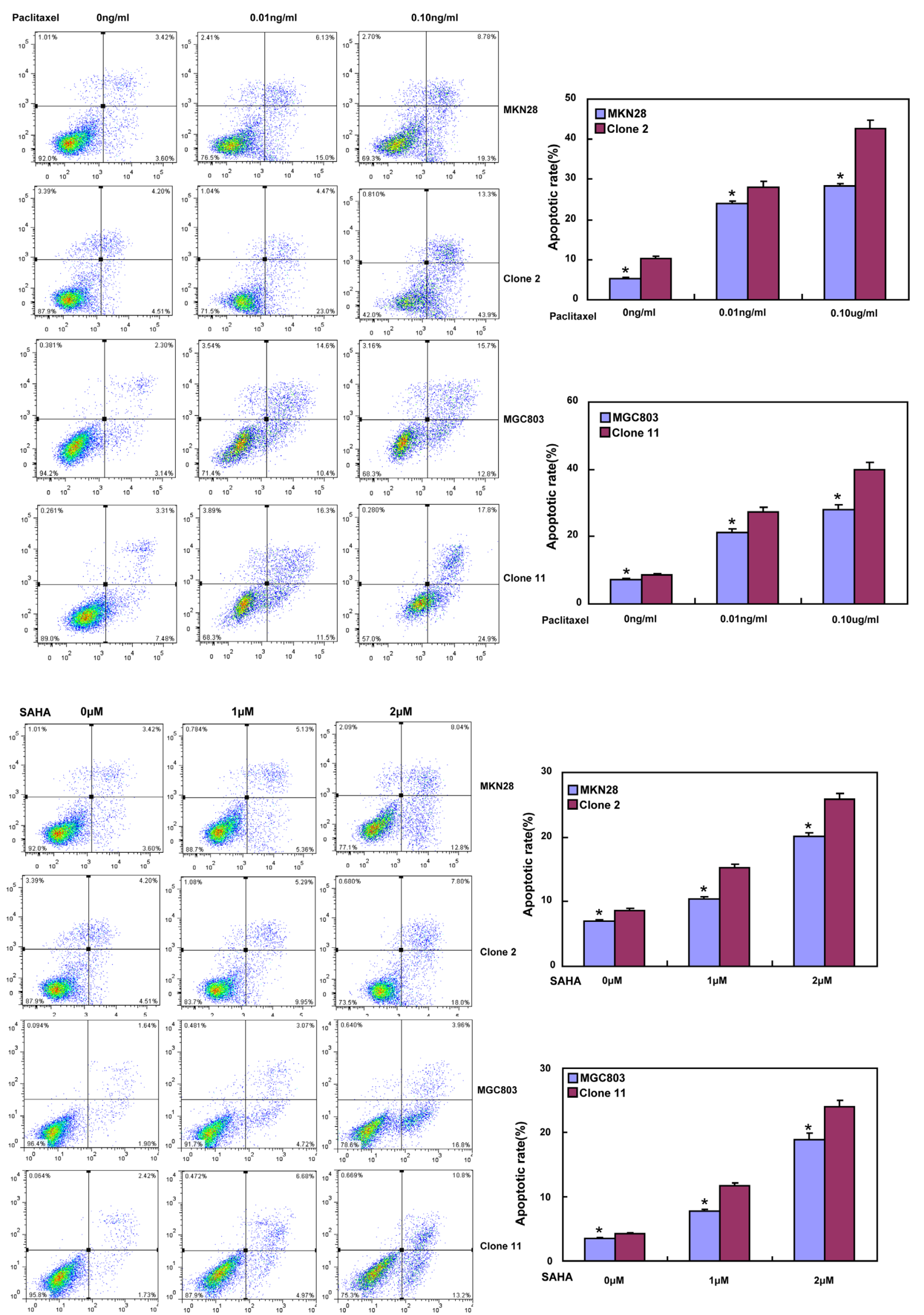
C
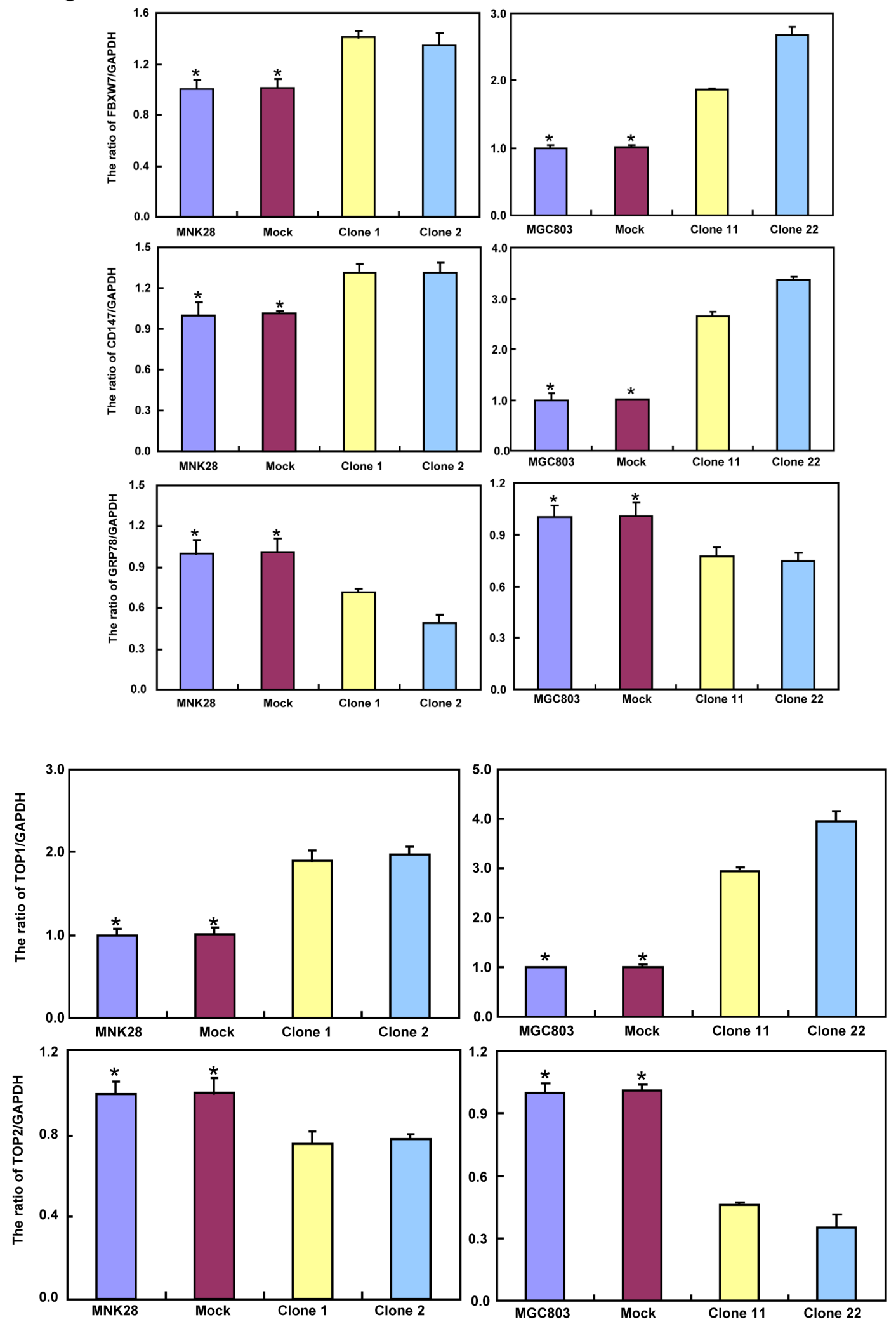

Figure 3: BTG3 overexpression enhances the sensitivity of gastric cancer cells to chemotherapeutic agents. exposed to cisplatin (DDP), MG132, paclitaxel, and SAHA, BTG3 transfectants showed a lower viability and a higher apoptotic level than the control in both concentration and time-dependent manners $(\boldsymbol{p}<0.05, \mathbf{A}$ and $\mathbf{B})$. The chemoresistance-related genes were screened by real-time RT$\mathrm{PCR}(\mathbf{C}) .{ }^{*} p<0.05$, compared with the transfectants. 

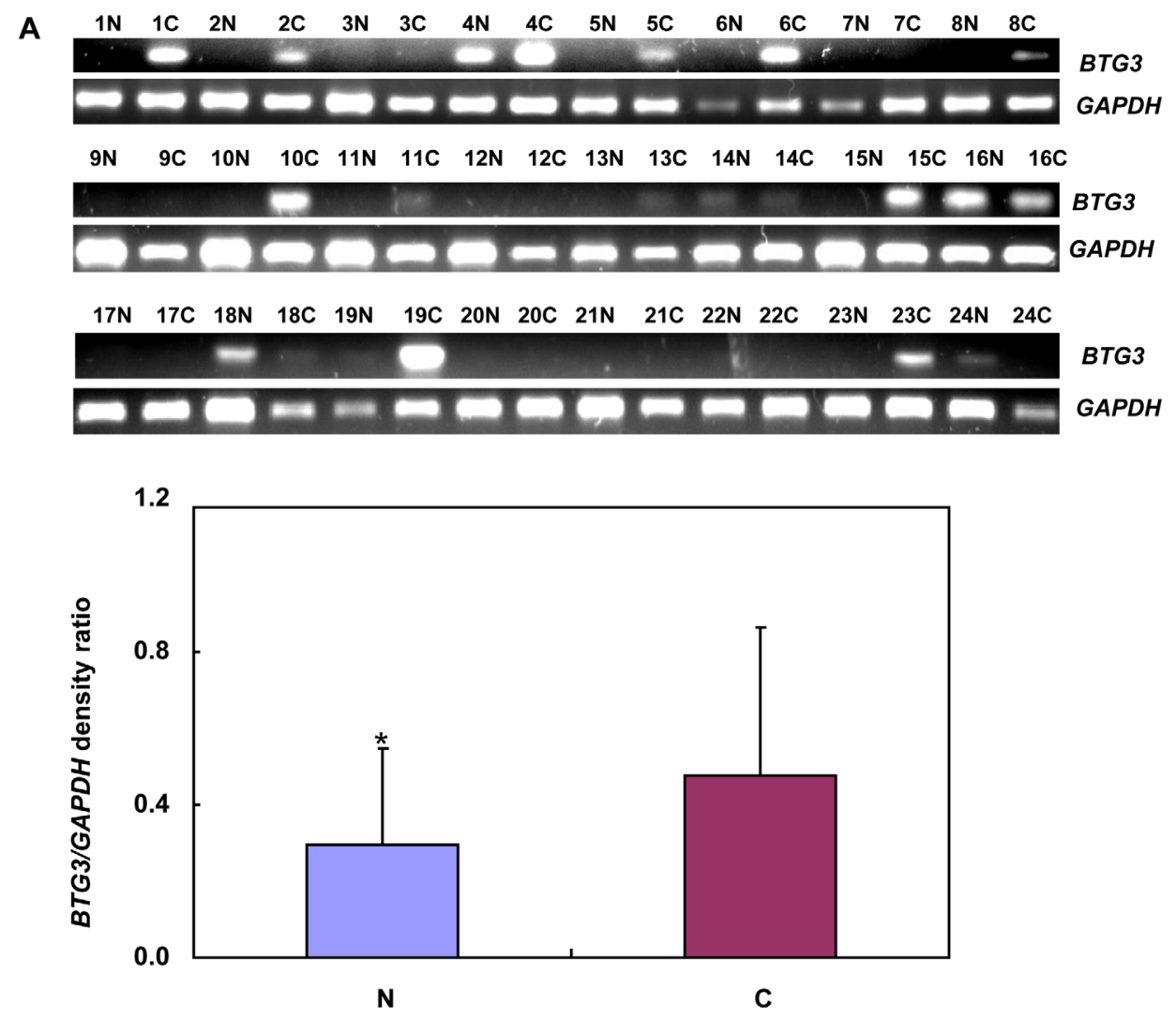

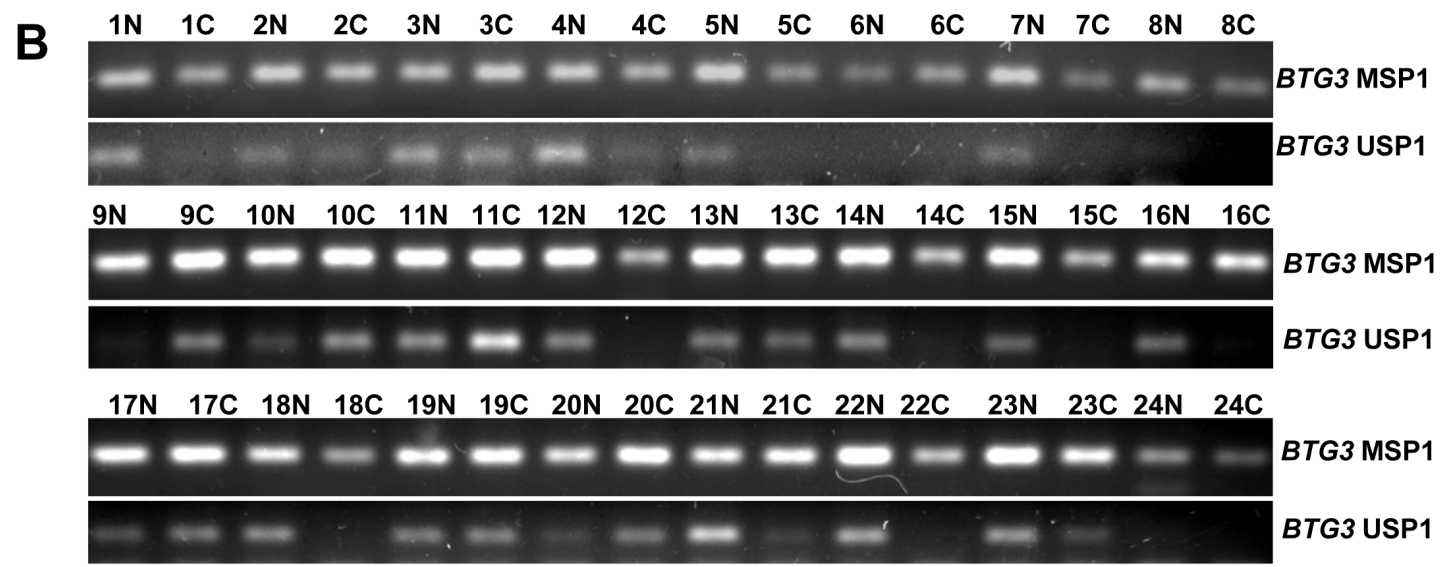

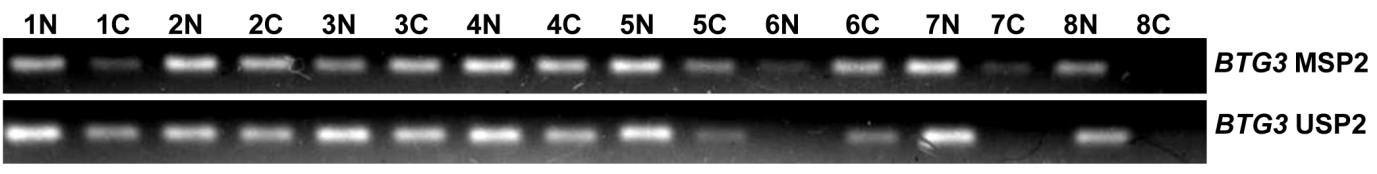

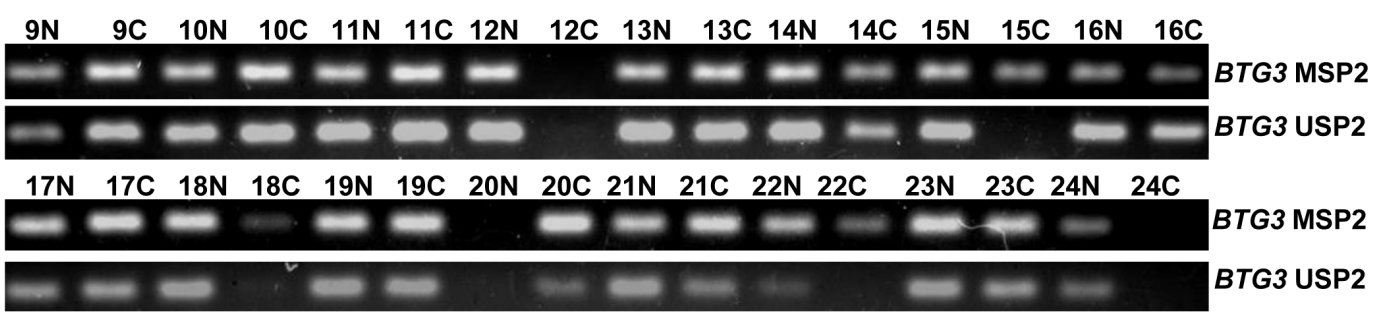




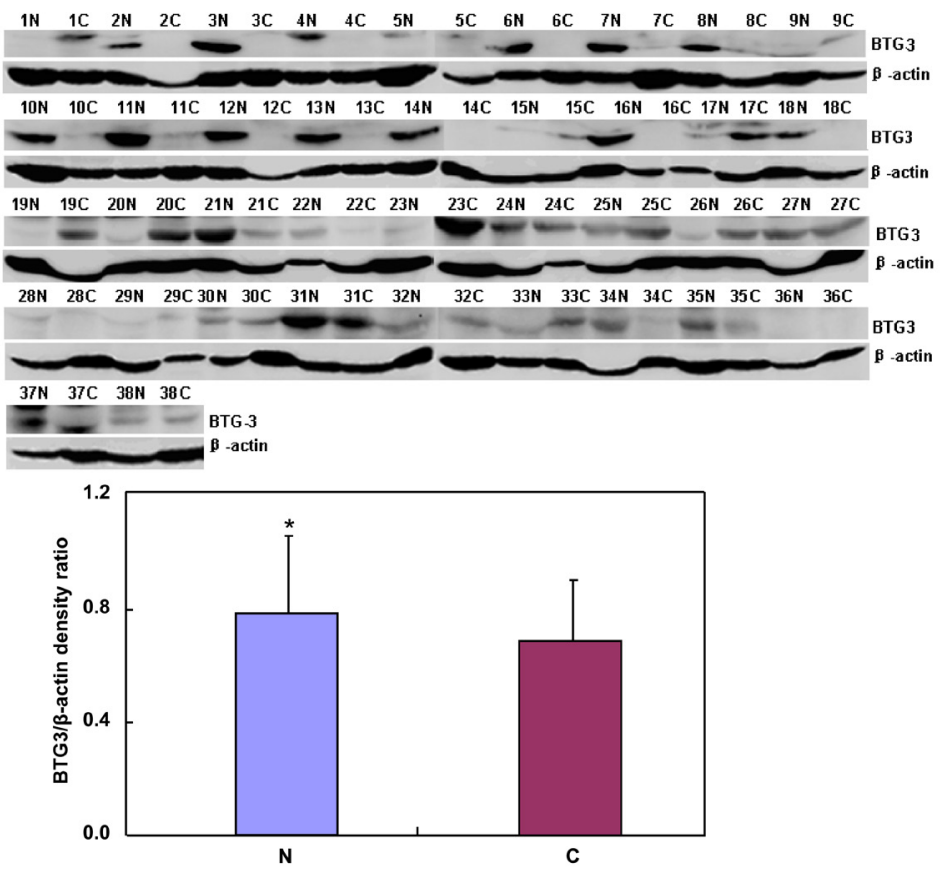

Figure 4: BTG3 expression and methylation in gastric cancer and matched mucosa. BTG3 cDNA was amplified by RT-PCR with $\boldsymbol{G A P D H}$ as an internal control. Densometric analysis showed higher BTG3 mRNA expression in carcinoma than paired mucosa (A). Methylation-specific PCR analysis was performed using primary tumors and matched mucosa tissues. The promoter methylation of BTG3 was detectable in all carcinoma or mucosa tissue (B). There was weaker BTG3 protein expression (29 kDa) in the tissue lysates of gastric cancer than matched mucosa with $\beta$-actin $(42 \mathrm{kDa})$ as an internal control $(\mathbf{C})$. Note: $\mathrm{M}$, methylated; U, unmethylated; N, non-neoplastic mucosa; $\mathrm{C}$, cancer; $\mathrm{NC}$, negative control; $p>0.05$.

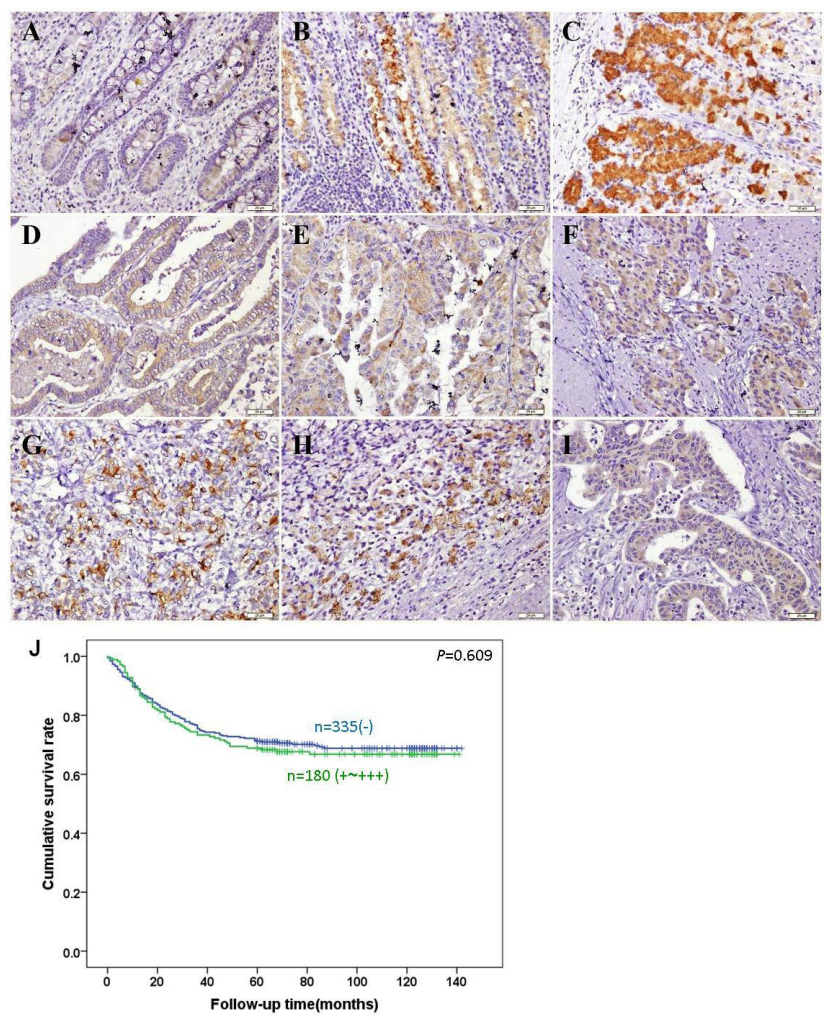

Figure 5: Immunohistochemical staining of BTG3 in gastric non-neoplastic mucosa and cancer. BTG3 protein was positively detected in the cytoplasm of the superficial epithelial cells (A), deep propria glands (B, C), well- (D), moderately- (E), poorly(F) differentiated, mucinous $(\mathbf{G})$, signet ring cell $(\mathbf{H})$ cancer and metastatic carcinoma in lymph node (I). Kaplan-Meier analysis showed no relationship between BTG3 protein expression and the cumulative survival rate of patients with gastric cancer $(p>0.05, \mathbf{J})$. 
Table 3: Multivariate analysis of clinicopathological variables for survival with gastric carcinomas.

\begin{tabular}{lcc}
\hline Clinicopathological parameters & Relative risk (95\%CI) & $\boldsymbol{p}$ value \\
\hline Age( $\geq 65$ years) & $1.373(0.996-1.891)$ & 0.053 \\
Sex(female) & $0.719(0.497-1.041)$ & 0.081 \\
Depth of invasion $\left(\mathrm{T}_{2-4}\right)$ & $2.088(0.689-6.329)$ & 0.193 \\
Lymphatic invasion(+) & $1.501(0.955-2.359)$ & 0.079 \\
Venous invasion(+) & $1.553(0.963-2.503)$ & 0.071 \\
Lymph node metastasis(+) & $2.041(1.094-3.808)$ & 0.025 \\
Distant metastasis(+) & $4.002(2.559-6.257)$ & $<0.001$ \\
TNM staging(III-IV) & $5.587(2.529-12.345)$ & $<0.001$ \\
Lauren's classification(IT/DT/MT) & $1.110(0.883-1.394)$ & 0.372 \\
BTG3 expression(+ +++) & $1.022(0.725-1.439)$ & 0.903 \\
\hline
\end{tabular}

$\mathrm{CI}=$ confidence interval, $\mathrm{TNM}=$ tumor-node-metastasis .

\section{A}

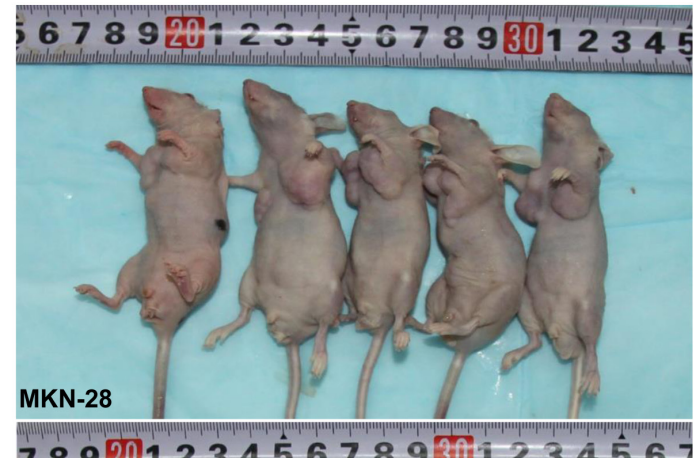

B
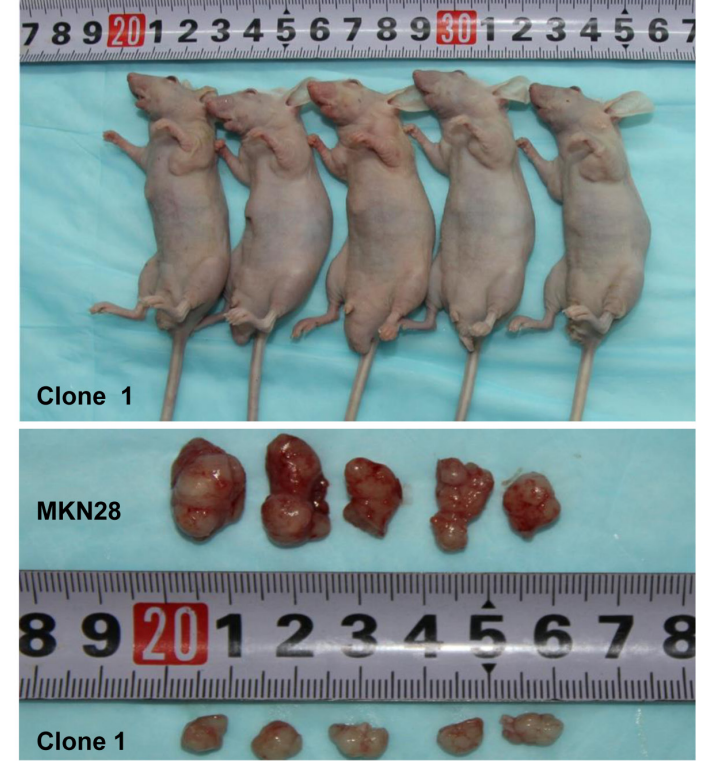

C

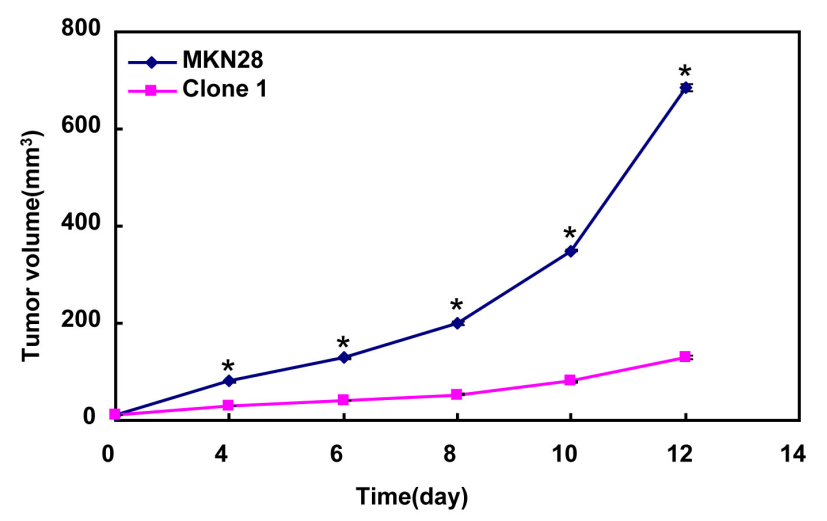

D

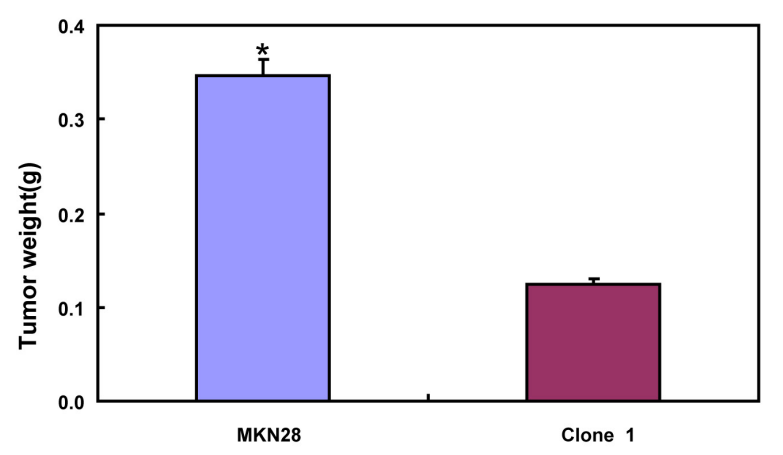




\section{G}
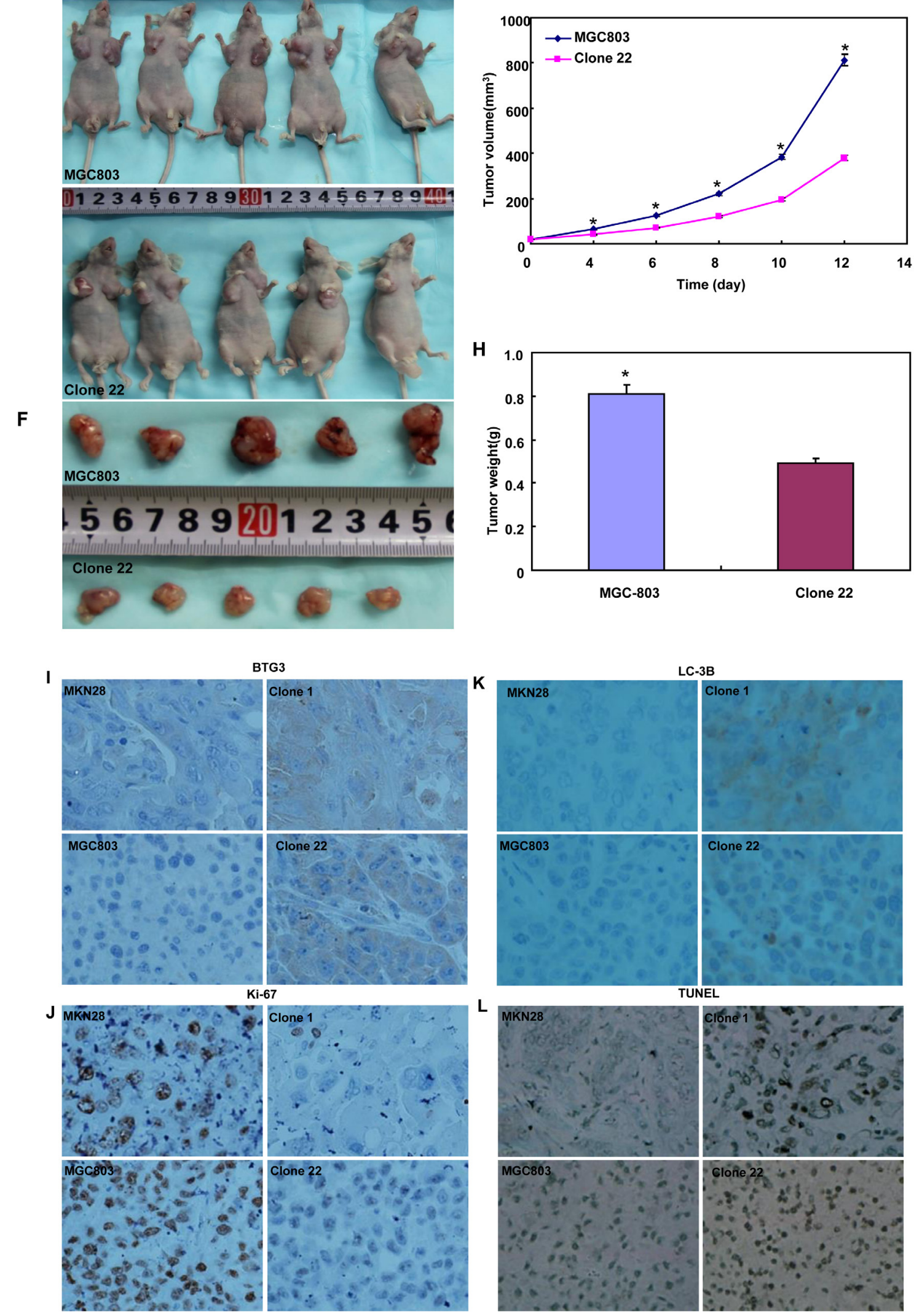

Figure 6: BTG3 suppresses the growth of gastric cancer cells in nude mice. The tumor volume and weight of MKN28 (AD) and MGC803 (E-H) cells were larger than their BTG3 transfectants. The transfectants showed stronger BTG3 (I) and LC-3B (K) expression, weaker ki-67 staining (J), and higher apoptotic signal by TUNEL (L) than the control. 
tissues [21]. Therefore, we concluded that alternative splicing and expression of BTG3 had cell specificity. Based on the findings of immunohistochemistry and Western blot, BTG3 expression was reduced in gastric cancer, compared with adjacent mucosa, indicating that down- regulated BTG3 expression enhanced the malignant transformation of gastric epithelial cells. In contrast, it was the converse for BTG3b mRNA, opposite to other reports [19, 21, 22]. MG132- induced BTG3 overexpression indicated that BTG3 hypoexpression might be due to its ubiquitin- proteasome degradation in gastric cancer [23]. We treated cells with 5-Aza and observed the restoration of BTG3 mRNA expression in gastric cancer cells, in line with the reports about breast, renal and prostate cancer cells [6, 16, 17]. However, no correlation was seen between BTG3 methylation and mRNA expression in gastric cancer and paired mucosa. Taken together, it was suggested that BTG3 methylation was partially responsible for its silenced expression.

Reportedly, BTG3 expression was negatively correlated with lymph node metastasis of lung cancer [21], distant metastasis of gastric [22] and hepatocellular [18] cancers. Provenzani et al. [24] found that BTG3 mRNA had about 1.83 fold higher in colon primary than metastatic carcinoma according to cDNA microarray. Here, we found that BTG3 expression was positively linked to venous invasion. BTG3 overexpression in vitro decreased migration, invasion and lamellipodia formation of gastric cancer cells with a down-regulated expression of MMP-9 and VEGF. These findings suggested that BTG3 overexpression might inhibit invasion and metastasis by reducing MMP-9 and VEGF expression. Additionally, a higher BTG3 expression was found in intestinal- than diffuse-type carcinoma, in line with a previous report [22]. Therefore, we hypothesize that differential BTG3 expression underlies the molecular mechanisms of both gastric carcinomas, which is also supported by ALP results. Mixed-type carcinoma showed BTG3 expression between the other two subtypes and no difference in BTG3 expression in its intestinal and diffuse components, supporting the opinion that different components of mixed-type carcinoma might originate from common stem cells [25].

In the present study, BTG3 overexpression in vitro inhibited proliferation, induced apoptosis and senescence, and $\mathrm{S} / \mathrm{G}_{2}$ arrest of gastric cancer cells, and in vivo suppressed the growth of gastric cancer cells by inhibiting proliferation, inducing apoptosis and autophagy. These data indicate that BTG3 might be employed as a molecular target of gene therapy to reverse the aggressive phenotypes of gastric cancer. Reportedly, both Cyclin D and E activate CDKs and are involved in $\mathrm{G}_{1}-\mathrm{S}$ transition, which is inhibited by $\mathrm{p} 21$ and $\mathrm{p} 27.14-3-3$ sequesters $\mathrm{Cdc} 25 \mathrm{C}$ to the cytoplasm to prevent the interactions with Cyclin B-Cdk1 necessary for $\mathrm{G}_{2} / \mathrm{M}$ transition [26]. BTG3-mediated $\mathrm{S} / \mathrm{G}_{2}$ arrest was positively linked to 14-3-3 overexpression and p21 hypoexpression regardless of CDK4 overexpression. The apoptosis-inducing effect of BTG3 might result from the overexpression of Bax, AIF, Caspase- 3 and -9 because AIF, Caspase-3 and -9 initiate apoptosis, and Bax opens the mitochondrial voltage-dependent anion channel for apoptosis [27]. Here, BTG3 overexpression was found to in vivo and vitro induce the autophagy of gastric cancer cells with Beclin 1 overexpression, indicating that BTG3mediated autophagy was dependent on beclin-1 expression [28]. Moreover, we demonstrated that BTG3 enhanced the sensitivity of gastric cancer cells to chemotherapeutic agents, which was positively associated with their apoptotic induction and the down-regulated expression of drug resistance genes (GRP78 and TOP2) [29, 30]. In the present study, we also found that BTG3 overexpression might ameliorate $\beta$-catenin, promote p38 and NF- $\kappa$ B expression in gastric cancer cells, indicating that BTG3 might target these signal pathways.

Although Ren et al. [22] reported that BTG3 expression was positively associated with favorable prognosis of gastric cancer, the BTG3-positive case number is too small $(n=8)$. In our group, BTG3 hypoexpression was found to correlate with a short disease-free time and overall survival of ovarian cancer patients [19]. However, no link between BTG3 expression and the survival of 515 gastric cancer patients was revealed even though stratified by depth of invasion. Multivariate analysis demonstrated that lymph node metastasis, distant metastasis and TNM staging were independent prognostic factors for overall gastric cancer. These findings suggested that BTG3 expression could not be employed to indicate the prognosis of gastric cancer patients.

In conclusion, down-regulated BTG3 expression might have impact on the malignant transformation of gastric epithelial cells and should be considered as a good biomarker for gastric carcinogenesis. Promoter methylation of BTG3 is partially responsible for its downregulated expression. BTG3 overexpression might reverse the aggressive phenotypes of gastric cancer cells and be employed as a target molecule for gene therapy.

\section{MATERIALS AND METHODS}

\section{Cell culture}

Gastric cancer cell lines, MKN28, AGS, BGC823, MGC803, MNK45 and SGC7901, KATO-III, HGC-27, GT-3TKB and STKM-2, SCH and gastric epithelial cell line, GES-1 come from Japanese Physical and Chemical Institute, Tokyo, Japan, Beijing Institute for Cancer Research, Beijing, China, and Cell bank of Chinese Academy of Sciences, Shanghai, China, respectively. 
They were maintained in RPMI 1640, MEM, DMEM or Ham F12 medium supplemented with 10\% fetal bovine serum (FBS), 100 units/mL penicillin, and $100 \mu \mathrm{g} / \mathrm{mL}$ streptomycin in a humidified atmosphere of $5 \% \mathrm{CO}_{2}$ at $37^{\circ} \mathrm{C}$. To demethylate the genomic DNA, cells were treated with $5 \mathrm{mmol} / \mathrm{L}$ of 5-aza-2'- deoxycytidine (5-Aza$\mathrm{dC}$, DNA demethylating agent) for $72 \mathrm{~h}$ and then harvested to extract DNA and RNA. To check the drug sensitivity, we exposed cells to cisplatin (a platinum-containing DNA crosslinker), MG132 (a proteasome inhibitor), paclitaxel (a mitotic inhibitor), and SAHA (a histone deacetylase inhibitor).

\section{Plasmid construction and transfection}

BTG3 gene was amplified using sense: 5'-ATGAAGAATGAAATTGCTGCCGTTG-3', antisense: 5'-GTGAGGTGCTAACATGTGAGGATT-3' and the template cDNA from MKN28. The PCR products was phosphorylated by BKL kit and ligated with EcoRVdigested and dephosphorylated pcDNA3.1. MKN28 and MGC803 cells were transfected with pcDNA3.1-BTG3, pcDNA3.1 vector or pEGFP-N1-LC-3B at $24 \mathrm{~h}$ after seeding on dishes, and selected by G418 with monoclone collection.

\section{Proliferation assay}

Cell counting Kit-8 (CCK-8, Japan) was employed to determine the number of viable cells. In brief, $2.5 \times 10^{3}$ cells/well were seeded on 96-well plate and allowed to adhere. At different time points, $10 \mu \mathrm{L}$ of CCK- 8 solution was added into each well of the plate and the plates were incubated for $3 \mathrm{~h}$ in the incubator and measured at $450 \mathrm{~nm}$.

\section{Cell cycle analysis}

The cells were trypsinized, collected, washed by PBS twice and fixed in cold $10 \mathrm{~mL}$ ethanol for more than $2 \mathrm{~h}$. Then, the cells were washed by PBS twice and incubated with $1 \mathrm{~mL}$ RNase $(0.25 \mathrm{mg} / \mathrm{mL})$ at $37^{\circ} \mathrm{C}$ for 1 $\mathrm{h}$. The cells were pelleted and resuspended in propidium iodide (PI) at a concentration of $50 \mu \mathrm{g} / \mathrm{mL}$ and incubated at $4{ }^{\circ} \mathrm{C}$ in the dark for $30 \mathrm{~min}$. Finally, flow cytometry was employed to examine PI signal.

\section{Apoptosis assay by flow cytometry}

Flow cytometry was performed with 7-aminoactinomycin (7-AAD) and FITC-labeled Annexin V (BD Pharmingen, San Diego, CA92121) to detect phosphatidylserine externalization as an endpoint indicator of apoptosis according to the manufacturer's instructions.

\section{Wound healing assay}

Cells were seeded at a density of $1.0 \times 10^{6}$ cells/ well in 6-well culture plates. After they had grown to confluence, the cell monolayer was scraped with a pipette tip to create a scratch, washed by PBS for three times and cultured in the FBS-free medium. Cells were photographed at $24 \mathrm{~h}$, and $72 \mathrm{~h}$ with the scratch area measured using Image software.

\section{Transwell chamber assays}

For invasive assay, $2.5 \times 10^{5}$ cells were resuspended in serum-free RPMI 1640, and seeded in the matrigelcoated insert on the top portion of the chamber (BD Bioscience, 354481). The lower compartment of the chamber contained $10 \%$ FBS as a chemoattractant. After incubated at $37^{\circ} \mathrm{C}$ and $5 \% \mathrm{CO}_{2}$ for $24 \mathrm{~h}$, cells on the membrane were scrubbed, washed with PBS, fixed in $100 \%$ methanol and stained with Giemsa dye. For migration assay, the procedures were the same as above excluding membrane-control insert (BD Bioscience).

\section{Alkaline phosphatase (ALP) activity}

ALP activity was used as a marker of colorectal differentiation. The cells were harvested, broken and subjected to the determination of ALP activity using Diagnostics ALP reagent (Sigma, USA). The protein content of the samples was determined Biorad protein assay kit (Biorad, USA). ALP activity was calculated as $\mathrm{U}$ per $\mu \mathrm{g}$ of protein.

\section{$\beta$-galactosidase staining}

$\beta$-galactosidase staining was performed with a senescence-associated $\beta$-galactosidase staining kit (Beyotime, Shanghai, China). Cells were washed three times with PBS and fixed with $4 \%$ paraformaldehyde for $15 \mathrm{~min}$ at room temperature. Next, cells were incubated overnight at $37^{\circ} \mathrm{C}$ in the dark with the working solution containing $0.05 \mathrm{mg} / \mathrm{mL} \mathrm{X-gal.} \mathrm{Finally,} \mathrm{cells} \mathrm{were}$ examined under a light inverted microscope (Olymphus).

\section{Immunofluorescence}

Cells were grown on glass coverslips, fixed with $4 \%$ formaldehyde for $10 \mathrm{~min}$, and permeabilized with $0.2 \%$ Triton X-100 for $10 \mathrm{~min}$ at room temperature. After washed with PBS, cells were incubated overnight at $4{ }^{\circ} \mathrm{C}$ with anti-BTG3 (Sigma, USA) or -LC-3B(Cell Signaling, USA). The Alexa Fluor ${ }^{\circledR} 488$ IgG (Invitrogen) was used as secondary antibody. Alexa Fluor ${ }^{\circledR} 568$ phalloidin 
(invitrogen) was employed to observe the lamellipodia. Nuclei were stained with $1 \mu \mathrm{g} / \mathrm{ml}$ DAPI (Sigma) at $37^{\circ} \mathrm{C}$. Finally, coverslips were mounted with SlowFade ${ }^{\circledR}$ Gold antifade reagent (Invitrogen) and observed under a laser confocal microscope (Olympus).

\section{Subjects and pathology}

Gastric adenocarcinomas $(n=613)$, adjacent non-neoplastic mucosa $(n=569)$ and lymph node with metastases $(n=180)$ were collected from surgical resection in the Affiliated Hospital of Kanagawa Cancer Center (Japan). The patients with gastric cancer were 427 men and 186 women $(24-87$ years, mean $=62.1$ years $)$. Among them, 265 cases have tumors accompanied with lymph node metastasis, 35 with distant metastasis. Intestinal and diffuse components of 114 mixed-type carcinomas were punched out for tissue microarray. Fresh gastric cancer and adjacent non-neoplastic mucosa were collected from our hospital and frozen in $-80^{\circ} \mathrm{C}$ until DNA, RNA and protein extraction. None of the patients underwent chemotherapy, radiotherapy or adjuvant treatment before surgery. They or their relatives provided written consent for use of tumor tissue for clinical research. The Ethical Committee of our university and Kanagawa Cancer Center approved the research protocol. We followed up the patients by consulting their case documents and through telephone.

All tissues were fixed in 10\% neutral formalin, embedded in paraffin and sections were cut at $4 \mu \mathrm{m}$. These sections were stained by hematoxylin-and-eosin (HE) to confirm their histological diagnosis and other microscopic characteristics. The tumor-node-metastasis staging for gastric cancer was evaluated according to the Union Internationale Contre le Cancer system [31]. Histological architecture of gastric carcinoma was expressed in terms of Lauren's classification [25]. Furthermore, tumor size, depth of invasion, lymphatic and venous invasion were determined.

\section{RT-PCR and direct sequencing}

Total RNA was extracted from gastric carcinoma and epithelial cell lines or cancer tissues using QIAGEN RNeasy mini kit (Germany). Two micrograms of total RNA was subjected to cDNA synthesis using AMV transcriptase and random primers (Takara, Japan). According to the Genbank, oligonucleotide primers for PCR were shown Supplementary Table 1. General and real-time RT-PCR amplification was performed using Hotstart Taq polymerase (Takara) and SYBR Premix Ex $\mathrm{Taq}^{\mathrm{TM}}$ II kit (Takara) respectively. The amplicons were electrophoresed in $2 \%$ agarose gel for $30 \mathrm{~min}$ and densitometric quantification was performed by comparison to GAPDH using Scion Image software. PCR products were purified with QIAquick gel extraction kit (QIAGEN) and then sequenced using a BigDye Terminator v 3.1 cycle sequencing kit (Applied Biosystems). The sequence data was compared with the human BTG3 cDNA using BLAST.

\section{Methylation-specific PCR (MSP)}

Genomic DNA was extracted from cells and tissues using QIAamp DNA Mini kit (QIAGEN). DNA was modified chemically with sodium metabisulphite. The bisulfite-modified DNA was amplified by using primer pairs that specifically amplify either methylated or unmethylated BTG3 as described previously [32]. The following methylated $B T G 3$-specific primers were used: sense: 5'-TAAAATATAGTAGGGCGGTTGTACG-3'; and antisense: 5'AAACTTCATAAAACACGAACTC G-3' (BTG3 MSP1: -474-596) or sense: 5'-AGTTGGGTTTAGAATCGTTATTC-3' and antisense: 5'-ACTTAATCCTTTCGACTATCTCGAC-3' (BTG3 MSP2: -608-709). The corresponding unmethylated primers ware sense: 5'-TAAAATATAGTAGGGTGGTTGTATGG-3' and antisense:

5'-AAACTTCATAAAAAACACAAACTCAAC-3'

(BTG3 USP1: -474-596) or sense: 5'-GAGTTG GGTTTAGAATTTGTTATTTTG-3' and anti-sense: 5'-ACTTAATCCTTTCAACTATCTCAAC-3' (BTG3 USP2: -608-709). MSP was performed for 40 cycles using hot-start polymerase (Takara).

\section{Western blot}

The cancer tissues and cells were subjected to protein extraction by homogenization or sonication in RIPA lysis buffer. Denatured protein was separated on SDS-polyacrylamide gel and transferred to Hybond membrane, which was then blocked overnight in 5\% skim milk in TBST. For immunoblot, the membrane was incubated for 15 min with the primary antibody (Supplementary Table 2). Then, it was rinsed by TBST and incubated with IgG conjugated to horseradish peroxidase (DAKO) for $15 \mathrm{~min}$. All the incubations were performed in a microwave oven to allow intermittent irradiation as recommended by $\mathrm{Li}$ et al. [33]. Bands were visualized with X film by ECL-Plus detection reagents (Santa Cruz, USA). Densitometric quantification of target proteins was performed with $\beta$-actin control using Scion Image software.

\section{Xenograft models}

Locally bred female BALB/c nude (nu/nu) mice, 6-8 weeks of age at implantation, were used. The animals were maintained under specific pathogen-free conditions, 
and food and water were supplied ad libitum. Housing and all procedures involving animals were performed according to protocols approved by the Committee for Animal Experiments guidelines on animal welfare of Liaoning Medical University. Subcutaneous xenografts were established by injection of $1 \times 10^{6}$ tumor cells per mouse to the axilla ( $n=10$ / group). Until the end of the experiment, one mouse from each group was randomly selected to be anesthetized, photographed, and sacrificed. For each tumor, measurements were made using calipers, and tumor volumes were calculated as follows: length $\times$ width $\times$ depth $\times 0.52$. The part of tumors were subsequently fixed in $4 \%$ paraformaldehyde for $24 \mathrm{~h}$, and then embedded in paraffin.

\section{Tissue microarray and immunohistochemistry}

Under the guaidance of HE-stained slides, a two mm-in-diameter tissue core per donor block was punched out and transferred to a recipient block with a maximum of 48 cores using a Tissue Microarrayer (Japan). Consecutive sections were deparaffinised with xylene, rehydrated with alcohol, and subjected to antigen retrieval by irradiating in target retrieval solution (DAKO) for $15 \mathrm{~min}$ with microwave oven (Oriental rotor Lmt. Co., Tokyo, Japan). All procedures were performed as described previously [34]. Omission of the primary antibody was used as a negative control.

As indicated in Fig. 3, BTG3 protein was positively localized in the cytoplasm. One hundred cells were randomly selected and counted from 5 representative fields of each section blindly by two independent observers. The inconsistent data were confirmed by both persons until final agreements were reached. The expression was graded and counted as follows: $0=$ negative; $1=1-50 \% ; 2=$ $50-74 \% ; 3 \geq 75 \%$. The staining intensity score was graded as follows: $1=$ weak; 2 = intermediate; and $3=$ strong. The scores for BTG3 positivity and staining intensity were multiplied to obtain a final score, which determines their expression $(-=0 ;+=1-2 ;++=3-5 ;+++=6-9)$.

\section{Terminal digoxigenin-labeled dUTP nick-end labeling (TUNEL)}

Cell apoptosis was assessed using TUENL, a method that is based on the specific binding O-TdT to the 3-OH ends of DNA, ensuring the synthesis of a polydeoxynucleotide polymer. For this purpose, ApopTag Plus Peroxidase In Situ Apoptosis Detection Kit (Chemicon) was employed according to the recommendation. Omission of the working strength TdT enzyme was considered as a negative control.

\section{Statistical analysis}

Statistical evaluation was performed using Spearman's correlation test to analyze the rank data and Mann-Whitney $\mathrm{U}$ to differentiate the means of different groups. Kaplan-Meier survival plots were generated and comparisons between survival curves were made with the log-rank statistics. Cox's proportional hazards model was employed for multivariate analysis. SPSS 10.0 software was applied to analyze all data and $p<$ 0.05 was considered statistically significant.

\section{ACKNOLEDGMENTS}

This study was supported by A Project Supported by Scientific Research Fund of Liaoning Provincial Education Department (LJQ2014093); National Natural Scientific Foundation of China (81172371; 81472544).

\section{CONFLICTS OF INTEREST}

The authors declare that they have no conflict of interest.

\section{REFERENCES}

1. Ang TL, Fock KM. Clinical epidemiology of gastric cancer. Singapore Med J. 2014; 55: 621-628.

2. Cancer facts and figures. American Cancer Society, 2014 edition.

3. Kawamura-Tsuzuku J, Suzuki T, Yoshida Y, Yamamoto T. Nuclear localization of Tob is important for regulation of its antiproliferative activity. Oncogene. 2004;23:6630-6638.

4. Winkler GS. The mammalian anti-proliferative BTG/Tob protein family. J Cell Physiol. 2010; 222: 66-72.

5. Guéhenneux F, Duret L, Callanan MB, Bouhas R, Hayette S, Berthet C, Samarut C, Rimokh R, Birot AM, Wang Q, Magaud JP, Rouault JP. Cloning of the mouse BTG3 gene and definition of a new gene family (the BTG family) involved in the negative control of the cell cycle. Leukemia. 1997; 11:370-375.

6. Yu J, Zhang Y, Qi Z, Kurtycz D, Vacano G, Patterson D. Methylation-mediated ownregulation of the B-cell translocation gene 3 (BTG3) in breast cancer cells. Gene Expr. 2008; 14:173-182.

7. Yamamoto N, Uzawa K, Yakushiji T, Shibahara T, Noma $\mathrm{H}$, Tanzawa $\mathrm{H}$. Analysis of the ANA gene as a candidate for the chromosome $21 \mathrm{q}$ oral cancer susceptibility locus. Br J Cancer. 2001; 84: 754-759.

8. Ou YH, Chung PH, Hsu FF, Sun TP, Chang WY, Shieh SY. The candidate tumor suppressor BTG3 is a transcriptional target of p53 that inhibits E2F1. EMBO J. 2007; 26: 39683980. 
9. Miyai K, Yoneda M, Hasegawa U, Toita S, Izu Y, Hemmi H, Hayata T, Ezura Y, Mizutani S, Miyazono K, Akiyoshi K, Yamamoto T, Noda M. ANA deficiency enhances bone morphogenetic protein-induced ectopic bone formation via transcriptional events. J Biol Chem. 2009; 284: 1059310600.

10. Yoshida Y, Hosoda E, Nakamura T, Yamamoto $T$. Association of ANA, a member of the antiproliferative Tob family proteins, with a Caf1 component of the CCR4 transcriptional regulatory complex. Jpn J Cancer Res. 2001; 92: 592-596.

11. Cheng YC, Lin TY, Shieh SY. Candidate tumor suppressor BTG3 maintains genomic stability by promoting Lys63linked ubiquitination and activation of the checkpoint kinase CHK1. Proc Natl Acad Sci U S A. 2013;110: 59935998.

12. Lin TY, Cheng YC, Yang HC, Lin WC, Wang CC, Lai PL, Shieh SY. Loss of the candidate tumor suppressor BTG3 triggers acute cellular senescence via the ERK-JMJD3-p16 (INK4a) signaling axis. Oncogene. 2012; 31:3287-3297.

13. Cheng YC, Chen PH, Chiang HY, Suen CS, Hwang MJ, Lin TY, Yang HC, Lin WC, Lai PL, Shieh SY. Candidate tumor suppressor B-cell translocation gene 3 impedes neoplastic progression by suppression of AKT. Cell Death Dis. 2015; 6:e1584.

14. Rahmani Z. APRO4 negatively regulates Src tyrosine kinase activity in PC12 cells. J Cell Sci. 2006; 119: 646658 .

15. Yoneda M, Suzuki T, Nakamura T, Ajima R, Yoshida Y, Kakuta S, Sudo K, Iwakura Y, Shibutani M, Mitsumori K, Yokota J, Yamamoto T. Deficiency of antiproliferative family protein Ana correlates with development of lung adenocarcinoma. Cancer Sci. 2009; 100: 225-232.

16. Majid S, Dar AA, Shahryari V, Hirata H, Ahmad A, Saini S, Tanaka Y, Dahiya AV, Dahiya R. Genistein reverses hypermethylation and induces active histone modifications in tumor suppressor gene B-Cell translocation gene 3 in prostate cancer. Cancer. 2010; 116: 66-76.

17. Majid S, Dar AA, Ahmad AE, Hirata H, Kawakami K, Shahryari V, Saini S, Tanaka Y, Dahiya AV, Khatri G, Dahiya R. BTG3 tumor suppressor gene promoter demethylation, histone modification and cell cycle arrest by genistein in renal cancer. Carcinogenesis. 2009; 30: $662-670$.

18. Lv Z, Zou H, Peng K, Wang J, Ding Y, Li Y, Ren X, Wang F, Chang R, Liang L, Ding Y. The suppressive role and aberrent promoter methylation of BTG3 in the progression of hepatocellular carcinoma. PLoS One. 2013; 8:e77473.

19. Deng BY, Zhao Y, Gou WF, Chen S, Miao XY, Takano Y, Zheng H. Aberrant BTG3 expression was linked to carcinogenesis, aggressiveness and prognosis of ovarian carcinoma. Tum Biol. 2013; 34: 2617-2624.

20. Yanagida S, Taniue K, Sugimasa H, Nasu E, Takeda Y, Kobayashi M, Yamamoto T, Okamoto A, Akiyama T.
ASBEL, an ANA/BTG3 antisense transcript required for tumorigenicity of ovarian carcinoma. Sci Rep. 2013; 3:1305.

21. Chen X, Chen G, Cao X, Zhou Y, Yang T, Wei S. Downregulation of BTG3 in non-small cell lung cancer. Biochem Biophys Res Commun. 2013; 437:173-178.

22. Ren XL, Zhu XH, Li XM, Li YL, Wang JM, Wu PX, Lv ZB, Ma WH, Liao WT, Wang W, Ding YQ, Liang L. Down-regulation of BTG3 promotes cell proliferation, migration and invasion and predicts survival in gastric cancer. J Cancer Res Clin Oncol. 2015; 141:397-405.

23. Sasajima H, Nakagawa K, Yokosawa H. Antiproliferative proteins of the BTG/Tob family are degraded by the ubiquitin-proteasome system. Eur J Biochem. 2002; 269: 3596-3604.

24. Provenzani A, Fronza R, Loreni F, Pascale A, Amadio M, Quattrone A. Global alterations in mRNA polysomal recruitment in a cell model of colorectal cancer progression to metastasis. Carcinogenesis. 2006; 27: 1323-1333.

25. Zheng HC, Li XH, Hara T, Masuda S, Yang XH, Guan YF, Takano Y. Mixed-type gastric carcinomas exhibit more aggressive features and indicate the histogenesis of carcinomas. Virchows Arch. 2008; 452: 525-534.

26. Williams G, Stoeber K. The cell cycle and cancer. J Pathol. $2012 ; 226: 352-364$.

27. Cosentino K. García-Sáez AJ. Mitochondrial alterations in apoptosis. Chem Phys Lipids. 2014; 181: 62-75.

28. Zhang MY, Gou WF, Zhao S, Mao XY, Zheng ZH, Takano Y, Zheng HC. Beclin 1 expression is closely linked to colorectal carcinogenesis and distant metastasis of colorectal carcinoma. Int J Mol Sci. 2014; 15: 14372 14385 .

29. Mahoney E, Lucas DM, Gupta SV, Wagner AJ, Herman SE, Smith LL, Yeh YY, Andritsos L, Jones JA, Flynn JM, Blum KA, Zhang X, Lehman A, et al. ER stress and autophagy: new discoveries in the mechanism of action and drug resistance of the cyclin-dependent kinase inhibitor flavopiridol. Blood. 2012; 120:1262-1273.

30. Housman G, Byler S, Heerboth S, Lapinska K, Longacre M, Snyder N, Sarkar S. Drug resistance in cancer: an overview. Cancers (Basel). 2014; 6:1769-1792.

31. Sobin LH. TNM Classification of Malignant Tumors, 7th edition, John Wiley \& Sons, Hoboken, New Jersey, 2009.

32. Yu J, Tao Q, Cheng YY, Lee KY, Ng SS, Cheung KF, Tian L, Rha SY, Neumann U, Rocken C, Ebert MP, Chan FK, Sung JJ. Promoter methylation of the Wnt/beta-catenin signaling antagonist Dkk-3 is associated with poor survival in gastric cancer. Cancer. 2009; 115:49-60.

33. Li W, Murai Y, Okada E, Matsui K, Hayashi S, Horie M, Takano Y. Modified and simplified western blotting protocol: use of intermittent microwave irradiation (IMWI) and 5\% skim milk to improve binding specificity. Pathol Int. 2002; 52: 234-238.

34. Kumada T, Tsuneyama K, Hatta H, Ishizawa S, Takano 
Y. Improved 1-h rapid immunostaining method using intermittent microwave irradiation: practicability based on 5 years application in Toyama Medical and Pharmaceutical University Hospital. Mod Pathol. 2004; 17: 1141-1149. 